This PDF is a selection from an out-of-print volume from the National Bureau of Economic Research

Volume Title: The Internationalization of Equity Markets

Volume Author/Editor: Jeffrey A. Frankel, editor

Volume Publisher: University of Chicago Press

Volume ISBN: 0-226-26001-1

Volume URL: http://www.nber.org/books/fran94-1

Conference Date: October 1-2, 1993

Publication Date: January 1994

Chapter Title: What Moves the Discount on Country Equity Funds?

Chapter Author: Gikas Hardouvelis, Rafael La Porta, Thierry A. Wizman

Chapter URL: http://www.nber.org/chapters/c6278

Chapter pages in book: (p. 345 - 403) 


\title{
What Moves the Discount on Country Equity Funds?
}

\author{
Gikas Hardouvelis, Rafael La Porta, and \\ Thierry A. Wizman
}

\subsection{Introduction}

Country funds are publicly traded investment companies (closed-end funds) that trade on the open market and, unlike domestic-equity funds, hold and manage portfolios concentrating in the equity markets of particular foreign countries. Throughout the late 1980 s and into the 1990 s, country funds were the fastest growing segment of the public fund universe, and a minor sensation on Wall Street. In December 1984 only four U.S.-listed country funds existed. By December 1992, forty-one funds traded in New York, each specializing in one of twenty-six countries, and altogether representing $\$ 4.3$ billion in market value of equity.'

Figure 8.1 illustrates the recent growth in the number of U.S.-based country funds by charting the dollar volume of initial public offerings (IPOs) by fund and by year from 1981 to 1992 . The rise in country fund IPOs parallels the growth in capitalization and liquidity in foreign stock markets. As of 1993, there were some forty foreign equity markets in the world, and non-U.S. equity

Gikas Hardouvelis is professor of finance in the School of Business at Rutgers University. Rafael La Porta is a lecturer in economics at Harvard University. Thierry A. Wizman is an investment officer and senior economist at Strategic Investment Partners, Inc. At the time this paper was written, he was an economist at the Federal Reserve Bank of New York.

The authors wish to thank the Federal Reserve Bank of New York for research support, and Maria Varvatsoulis and Stuart Schweidel for research assistance. Special thanks go to Andrei Shleifer, Robert Vishny, and Judy Chevalier. Jeffrey Frankel, Vihang Errunza, Rob Neal, Michael Boldin, David Laster, Peter Gray, and participants at the conference provided helpful comments. The views expressed in this article, however, are the authors' own and do not reflect the views of the Federal Reserve Bank of New York or the Federal Reserve System and its staff.

1. The precursors to the modern publicly traded country funds were the internationally diversified investment trusts first formed in Great Britain in the 1860s. They originally invested in foreign government bonds, and eventually diversified into foreign industrial bonds, land mortgages, and American railroad debentures. Foreign equity funds in the United States have a history dating back to 1951-52 with the Israel Development Corporation and the Canadian Fund. During the 1980s, the London and Hong Kong stock exchanges also emerged as centers for country fund trading. 


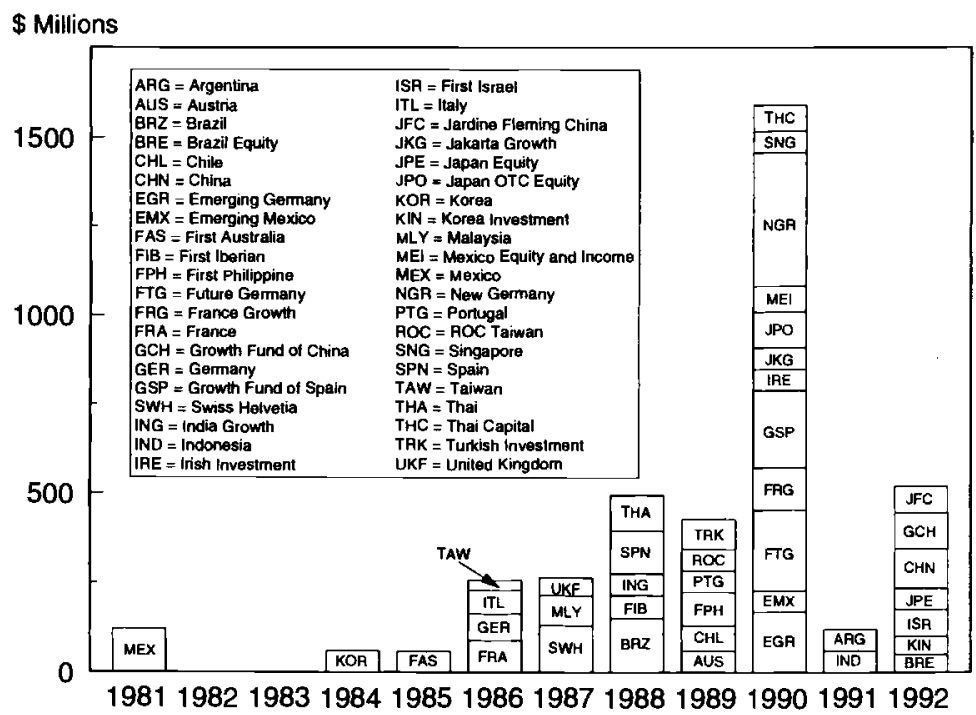

Fig. 8.1 Initial public offerings of country funds: 1981-92

Source: Moody's Financial Handbook.

market capitalization was twice as great as U.S. capitalization. The country funds allow U.S.-based investors to participate in the expansion of foreign markets by providing a managed and diversified portfolio at a minimal transaction cost, and without the use of foreign currencies to make settlements. ${ }^{2}$

Country funds have exhibited periods of high returns as well as high volatility. Like most publicly traded funds, country funds typically trade at substantial discounts to the underlying value of the portfolio they hold (the fund's net asset value or NAV). The discount, however, is not constant, and varies substantially over time. Anecdotal evidence suggests that the unusual volatility in country fund prices can be attributed to volatility in the discounts. Consider the changes in the discount/premium of the Mexico Fund from 1986 to 1993, shown in figure 8.2A. The fund typically traded at a discount in the range of 0 percent to 40 percent. The discount varies substantially from week to week, occasionally turning into a premium. Variation in the Mexico Fund's discount is typical of many country funds and cannot be easily attributed to identifiable news events.

In addition to high volatility, some country funds have also experienced crashlike episodes unrelated to the state of the foreign stock market. Figure 8.2B shows the behavior in the discount of the Germany Fund. This country fund was subject to especially volatile swings in the winter of $1989-90$ as the

2. Recent work on international investment has stressed the role of foreign and emerging markets in effective diversification (Divecha, Drach, and Stefek 1992). Diwan and Galindez (1991) and Diwan, Errunza, and Senbet (1992) discuss the role of country funds from the host country's perspective. 


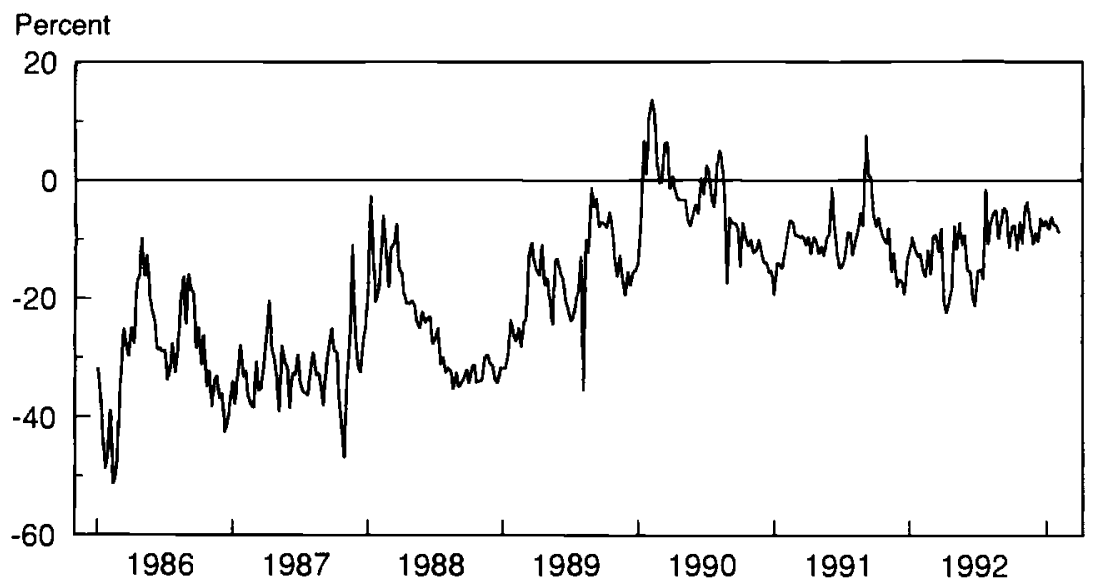

Fig. 8.2A Weekly percentage discount or premium of the Mexico Fund

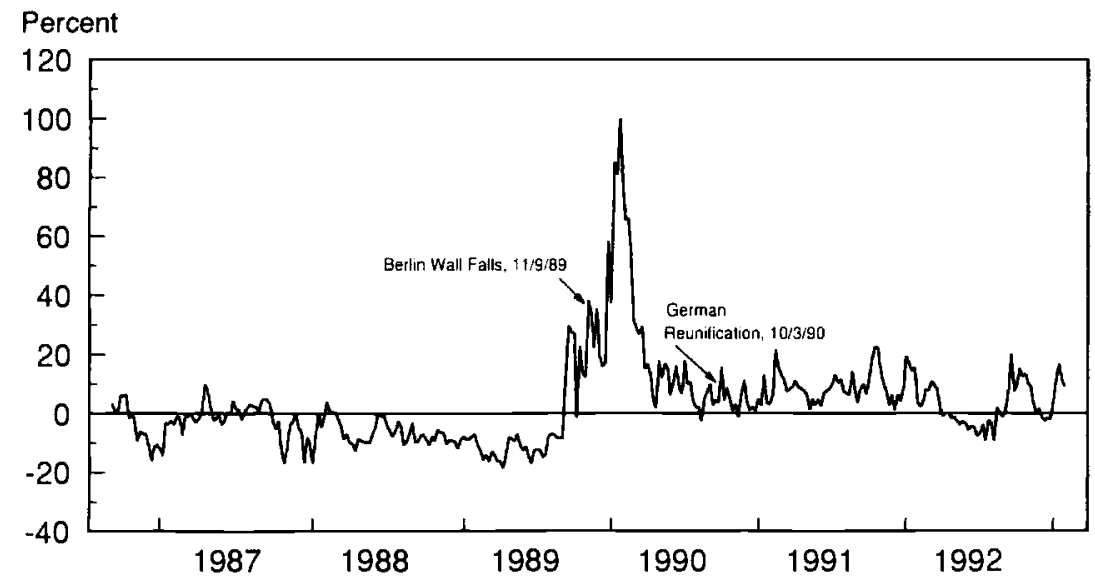

Fig. 8.2B Weekly percentage discount or premium of the Germany Fund

premium rose to 100 percent after the fall of the Berlin Wall. Popular accounts of the episode attributed it to speculation on the part of investors waiting to "cash in" on new investment opportunities in Germany. What made the behavior doubly impressive was that it seemed to carry a cross-border contagion. Between November 9 and January 26, the Austria (AUS), the First Iberian (FIB), the Italy (ITL), the Swiss (Helvetia) (SWH), and the far-flung Malaysia (MLY), Thai (THA), and Taiwan (TAW) funds experienced dramatic but shortlived increases (decreases) in the premium (discount). ${ }^{3}$ Figure 8.2B suggests

3. The rise (fall) in the premiums (discounts) between November 3, 1989 and January 26, 1990 were as follows: AUS: 77 percent, FIB: 54 percent, SWH: 21 percent ITL: 29 percent, MLY: 55 percent, THA: 60 percent, TAW: 27 percent. 
that the events of 1989 have not yet dissipated for the Germany Fund. Whereas the fund traded at a discount of between 20 percent and 0 percent prior to November 1989, on a typical day following October 3, 1990, the fund traded at a premium.

Discounts contradict the value-additivity principle of efficient and frictionless capital markets. However, as Rozeff (1991) notes, truly frictionless markets do not exist. In efficient and frictionless markets, investment companies would not arise because they could not offer diversification services at a lower cost than zero, and no benefit could accrue to professional managers. Therefore, because the funds exist, they should be expected to trade at prices different than the NAV. Intriguing issues, of course, relate to the source of the frictions and inefficiencies that give rise to the existence, persistence, and time-variation in discounts (Brauer 1992).

The behavior of country fund discounts may reflect items that preclude costless cross-border transactions: official and unofficial barriers to capital movements, transaction costs, time mismatch in trading hours, or risk arising from the time required to complete a full arbitrage transaction. Barriers to capital movements, for example, could potentially explain the variability of the discount: in a segmented market, the price of a U.S.-based country fund is determined by the diversification needs of U.S. investors, whereas the NAV of the fund is determined by the diversification needs of the investors in the fund's host country. Put differently, the relevant (priced) systematic risks of the fund and its net assets are based on different benchmark portfolios in segmented markets. Weekly changes in the gap between price and net asset value could be generated by time variation in the difference between these risk measures.

Alternatively, discounts may be caused not by market frictions but rather by the mechanism of public trading. This explanation emphasizes the role of irrational investors, called "noise traders" or "ordinary investors," who interact in the market with rational investors (DeLong et al. 1990; Shiller 1984; Zweig 1973). Lee, Shleifer, and Thaler (1991) evaluate empirically this explanation of the behavior of fund discounts using data on domestic-equity funds. An important feature of this model is the variation in the demand of noise traders caused by shifts in "sentiment" or by "misperceptions" of fundamental value. DeLong et al., for example, characterize sentiment as the excess of investor return expectations over the mathematical expectations. While variation in sentiment potentially explains variation in country fund discounts, DeLong et al. add structure to their model by introducing the idea of noise-trader risk. If variation in investor sentiment or misperceptions on individual assets vary systematically, then assets subject to sentiment will be riskier and underpriced, on average, relative to fundamentals.

The first aim of the present paper is to characterize some empirical regularities of country fund prices. Owing to the recent emergence of country funds, relatively little empirical work has been conducted on their pricing; much of the evidence remains anecdotal. In contrast, there is a large body of empirical 
literature on the behavior of prices of domestic-equity funds. A second aim is to examine whether the sentiment model is consistent with closed-end fund pricing. ${ }^{4}$ Accordingly, the paper relies on the noise-trader model to motivate and guide the empirical relationships that we examine using the country funds. The empirical regularities we uncover present a challenge to asset pricing models that assume investor rationality and market efficiency, but this challenge is left to future research.

Country funds have a number of distinct advantages over domestic-equity funds in determining the validity of models based on investor sentiment. First, country fund discounts are better suited to detect movements in sentiment than domestic-equity fund discounts. As noted by Chopra, Lee, Shleifer, and Thaler (1993), the discounts of domestic-equity funds may not fully capture swings in sentiment because the same U.S. investor sentiment affects both the price of the fund and its underlying assets, so that swings in investor sentiment leave the discount largely intact. U.S.-based country funds, on the other hand, may not suffer from this problem; while their prices would be subject to U.S. investor sentiment, prices of their underlying assets (which determine the NAV) will be determined largely on foreign equity markets, which, presumably, are not subject to U.S. investor sentiment. Variation in the discounts of the country funds would, therefore, reflect any differences in sentiment between U.S. and foreign-based investors, resulting in both more volatility in discounts and greater statistical power.

Second, compared with domestic-equity closed-end funds, the comovement of country fund discounts provides a stronger indication of common variation in sentiment than of common variation in fundamentals. The underlying assets of domestic-equity funds are U.S. stocks, and thus a large component of their prices or NAVs is due to common variation in U.S. fundamentals. On the other hand, the underlying assets of different country funds are equities of different countries, and thus common cross-country variation in fundamentals represents a much smaller fraction of the total variation in country fund discounts. Finding a strong common component in discounts across country funds is, therefore, more likely to be the result of common variation in U.S. investor sentiment than the result of common cross-country variation in fundamentals.

Finally, compared with domestic-equity funds, country funds enable us to analyze a richer array of factors that may potentially drive the movement of investor sentiment and misperceptions over time. Such factors can be changes in foreign exchange rates, host country stock prices, world stock prices, and U.S. stock prices.

The rest of the paper is organized as follows: Section 8.2 reviews the stylized facts regarding the pricing of publicly traded funds. The same section extends the model of DeLong et al. in a multiasset context. The predictions of

4. In this regard, the work presented in Bodurtha, Kim, and Lee (1993) is in the same spirit and has results similar to ours. 
the model subsequently serve as a heuristic guide for our empirical work. Section 8.3 discusses our data and its sources and provides some additional institutional facts about country funds. Section 8.4 focuses on the time-series behavior of country fund prices. Section 8.5 explores the determinants of the returns on country funds. In particular, the section examines the response of the fund returns and discounts to financial variables such as foreign stock market returns, exchange rates, and U.S. stock returns. Section 8.6 summarizes our main conclusions.

\subsection{The Closed-End Fund Puzzle and the Noise-Trader Model}

\subsubsection{The Puzzle}

Unlike an open-end mutual fund, the shares of a publicly traded fund cannot be redeemed at net asset value and thus the link between the market value of the fund shares and the market value of the fund's NAV is tenuous. The "closed-end fund puzzle" refers to the finding that publicly traded funds always trade either at a discount or at a premium to their respective NAVs. The empirical literature finds that discounts are the norm. ${ }^{5}$

The existence and persistence of discounts seem to contradict the valueadditive principle of frictionless efficient capital markets. Moreover, no generally accepted explanation for the existence of premia and discounts exists. Explanations of this puzzle consistent with market efficiency and frictionless capital markets emphasize that the fund's net asset value may be mismeasured. For example, the reported NAV does not correctly account for management fees, illiquid "letter stock" in the portfolios, or the implicit capital-gains tax liability on unrealized price appreciation (see Boudreaux 1973 and Roenfelt and Tuttle 1973). However, the above sources of NAV mismeasurement can only partially explain the existence of persistent discounts on domestic-equity funds (Malkiel 1977; Lee, Shleifer, and Thaler 1991). Moreover, anecdotal evidence and academic research suggest that the mismeasurement hypotheses are unable to explain the variation in discounts across funds. ${ }^{6}$

In light of the problems in explaining the discounts, both generally and for country funds, Brauer (1992) stresses that further insights might be derived from research into the behavior of discounts through time. In this regard, Lee, Shleifer, and Thaler summarize four stylized facts concerning the time-series properties of domestic-equity closed-end funds, which cannot be explained by the mismeasurement hypothesis. ${ }^{7}$ Lee, Shleifer, and Thaler assert that any the-

5. Lee, Shleifer, and Thaler (1991), for example, examine a sample of twenty primarily domestic-equity stock funds and find that on average, the value-weighted discount on a portfolio of these funds trades at 10 percent less than the NAV over the period 1965-85.

6. Ammer (1990), for example, finds that the organizational expenses of British closed-end funds fail to play a role in the time-series or cross-sectional variation in discounts.

7. The stylized facts are as follows. First, new funds are typically priced at a premium reflecting underwriting and organizational costs. Subsequent to the IPO, funds tend to underperform relative to other IPOs and returns on the net asset value (Peavey 1990 and Weiss 1989). Six months follow- 
ory purporting to explain the existence of discounts must also be consistent with the stylized facts. However, the standard explanations cannot, separately or together, explain the ancillary pieces of the puzzle represented by the stylized facts. Lee, Shleifer, and Thaler demonstrate that the noise-trader model of DeLong et al. is not only consistent with the stylized facts, but implies them as well. Using a sample of primarily domestic-equity funds, Lee, Shleifer, and Thaler test those implications of the model which had not been derived or tested in the context of other theories of discounts.

\subsubsection{A Model of Investor Sentiment}

We now present a general multiasset version of a model with both rational (informed) investors and noise traders in order to motivate the implications of the sentiment model for country fund data. The economy contains one riskless asset, which earns a gross rate of return $l+r$, and $K$ risky assets, which we interpret as equities. The risky assets are in fixed supply which we denote by the $K$-dimensional vector $\mathrm{\iota}$. The number of shares of each risky asset is normalized to equal one, so that $\iota$ is a vector of ones. We let $\boldsymbol{P}_{t}$ and $\boldsymbol{D}$, denote the $K$ dimensional vectors of the prices and dividends paid on the $K$ risky assets, respectively. The $j^{\text {th }}$ element of $\boldsymbol{P}_{t}$ and $\boldsymbol{D}_{t}$ represents the price and dividend of the $j_{t h}$ asset, respectively. As in DeLong et al. (1990) and Shiller (1984), we postulate the existence of two representative agents: a rational (informed) investor and an ordinary investor (noise trader). Informed investors are present in the market in measure $1-\mu$; noise traders are present in measure $\mu$.

The informed agent chooses his portfolio to maximize his perceived expected utility given his own beliefs about the mean of the normally distributed with-dividend price vector $\left(\boldsymbol{P}_{t+1}+\boldsymbol{D}_{t+1}\right)$ :

$$
\lambda_{t}^{\prime}=\Omega_{t}^{-1}\left[E_{t}\left(\boldsymbol{P}_{t+1}+\boldsymbol{D}_{t+1}\right)-(1+r) \boldsymbol{P}_{t}\right] / \gamma .
$$

Here $\lambda_{t}^{I}$ is a $K$-dimensional vector representing the demand for shares by the informed investor, while $\Omega$ is the variance-covariance matrix of $\left(\boldsymbol{P}_{t+1}+\boldsymbol{D}_{t+1}\right)$, and $\gamma$ is the coefficient of absolute risk aversion. The $j^{\text {th }}$ element in $\lambda_{t}^{I}$ represents the number of shares of risky asset $j$ demanded by the representative informed agent.

Whereas informed agents respond only to expected returns optimally forecast, noise traders respond to another factor denoted by $\rho_{t} . \rho_{t}$ is assumed to enter the demand of noise traders in linear fashion and represents either an over- or underreaction to news about fundamentals or represents a "fad." For

ing the IPO, the average fund trades at a significant discount. Second, Brauer (1984) and Brickley and Schallheim (1985) show that when funds announce plans to open-end or liquidate (and distribute the proceeds to shareholders) the discounts move toward zero and positive returns accrue to fund shareholders. Third, fund prices appear to be excessively volatile: the variance of fund returns exceeds the variance of returns on the underlying assets (Sharpe and Sosin 1975). Finally, portfolios of funds with large discounts subsequently generate excess risk-adjusted returns (Thompson 1978), and abnormal profits can be generated using the information content of publicly disclosed discounts (Richards, Fraser, and Groth 1980; Anderson 1986). 
now, we adopt DeLong et al.'s (1990) assumption that $\rho_{t}$ captures the noise trader's misperception of the expected with-dividend price vector of the risky assets. Specifically, the demand of the noise trader is given by

$$
\lambda_{t}^{N}=\Omega_{t}^{-1}\left[E_{t}\left(\boldsymbol{P}_{t+1}+\boldsymbol{D}_{t+1}\right)+\rho_{t}-(1+r) \boldsymbol{P}_{t}\right] / \gamma
$$

That is, if the rational expectation of $\boldsymbol{P}_{t+1}+\boldsymbol{D}_{t+1}$ is given by $\left(\boldsymbol{P}_{t+1}+\boldsymbol{D}_{t+1}\right)$, then the noise trader's expectation is given by $\left(\boldsymbol{P}_{t+1}+\boldsymbol{D}_{t+1}\right)+\rho_{t}$. The two investors' problems are similar except for the term $\rho$ in (2). When the noise trader is "bullish" on risky asset $j$, the $j^{\text {th }}$ element of the vector $\rho$ is large, and he will nominally demand more shares of that asset than the rational investor. The demand functions reflect a crucial assumption made by DeLong et al.: that investors' horizons are short, so that they care only about their wealth, one period hence. $^{8}$

Market clearing requires: $(1-\mu) \lambda{ }^{I}+\mu \lambda_{t}^{N}=\iota$. Substituting the demand functions into the equilibrium condition yields required excess returns:

$$
E_{t}\left(\boldsymbol{R}_{t+1}\right)=E_{t}\left(\boldsymbol{P}_{t+1}+D_{t+1}\right)-(1+r) \boldsymbol{P}_{t}=\gamma \Omega_{t} \iota-\mu \rho_{t}
$$

Equation (3) suggests that equilibrium returns are relatively high when noise traders are bearish. In other words, ordinary investors systematically "mistime" the market. The limit of (3) as the measure of noise traders, $\mu$, goes to zero is the ordinary efficient markets model.

To derive useful closed-form solutions, we assume that both dividends and sentiment follow first-order autoregressive processes. Thus, for any asset $j, j=$ $1, \ldots, K$, that earns dividends or is subject to sentiment:

$$
\begin{gathered}
d_{j, t+1}=\phi_{j} d_{j, t}+v_{j, t+1} ; v_{j, t+1}=z_{t+1}^{d}+\varepsilon_{j, t+1}^{d} \\
\boldsymbol{\rho}_{j, t+1}=\Psi_{j} \boldsymbol{\rho}_{j, t}+u_{j, t+1} ; u_{j, t+1}=z_{t+1}^{\mathrm{p}}+\varepsilon_{j, t+1}^{\mathrm{p}} .
\end{gathered}
$$

The disturbance terms, $v$ and $u$, are assumed to be normally distributed, white noise processes. Each error term contains two components. The systematic component, denoted by $z^{d}$ for fundamentals, and by $z^{\rho}$ for sentiment, is a white noise, normally distributed shock common to all assets. $z^{d}$ and $z^{p}$ may be contemporaneously correlated. The idiosyncratic terms, denoted by $\varepsilon^{d}$ for fundamentals and by $\varepsilon^{\rho}$ for sentiment, are white noise, normally distributed errors that are contemporaneously uncorrelated across assets and between sentiment and fundamentals. Equations (4) and (5) embody DeLong et al.'s assumption that noise traders' sentiment is stochastic and cannot be perfectly forecasted by rational investors. Closed-form steady-state solutions for prices and expected returns on any risky asset $j$ are given by

8. The demands of the two representative agents can be derived as the first-order condition of a problem in which each agent maximizes the expected value of an exponential utility function in next-period wealth and where asset prices are normally distributed (DeLong et al. 1990). 


$$
\begin{gathered}
p_{j, t}=\frac{\beta \phi_{j}}{1-\beta \phi_{j}} d_{j, t}+\frac{\beta}{1-\beta \Psi_{j}} \mu \rho_{j, t}-\frac{\gamma}{1-\beta \phi_{j}}\left(\frac{\sigma_{v}, w}{r}\right) \\
-\frac{\gamma \beta}{1-\beta \psi_{j}}\left(\frac{\sigma_{u_{j}, w}}{r}\right) \\
E_{r}\left(R_{j, t+1}\right)=\gamma \sigma_{R_{j}, w}-\mu \rho_{j, t}=\frac{\gamma \beta \phi_{j}}{1-\beta \phi_{j}} \sigma_{v_{j}, w}+\frac{\gamma \beta \psi_{j}}{1-\beta \psi_{j}} \sigma_{u_{j}, w}-\mu \rho_{j, t},
\end{gathered}
$$

where the $\sigma$ terms represent the steady-state covariances of the error terms from (4) and (5) with aggregate wealth $W$, where $W=\sum_{k=1}^{K}\left(p_{k}+d_{k}\right)$; and $\beta=$ $(1+r)^{-1}$.

If variation in sentiment for asset $j$ is not idiosyncratic, but instead reflects systematic variation in noise trader sentiment which affects other assets, or is positively correlated with innovations in fundamentals, then the covariance term $\sigma_{u j, W}$ in (6) and (7) will be positive. By raising systematic risk, variation in noise trader sentiment lowers the price of the risky asset $j$, and correspondingly raises the expected return. Note that the expected return on asset $j$ will be higher even if noise traders are neither currently bullish nor bearish $\left(\rho_{j, t}=\right.$ 0 ), because the systematic risk attached to noise trader activity in asset $j$ remains.

The second term in (6) captures the "price pressure" effect of sentiment. As soon as fundamental (or nonfundamental) news gives rise to an increase in sentiment, the price of the stock will jump to reflect not only what rational investors think the announcement means for future dividends but also what they think the announcement means for current and future demand by ordinary investors. From (7), the model has the property that any variables dated $t$ or earlier which are known to reflect current noise trader sentiment will also help predict returns.

\subsubsection{Fund Discounts and the Noise Trader Model}

A crucial assumption needed to apply the sentiment model to the pricing of publicly traded funds is that publicly traded funds and their underlying assets are not subject to the same variation in noise trader sentiment. One way to rationalize this is to assume that the fund and its underlying assets have different investor clienteles, and that one clientele is subject to swings in sentiment and misperceptions while the other is not. In the context of the model presented above, we can think of assets not subject to noise trader sentiment as falling within a nontrivial subset of all risky assets, call it $K^{\prime}$, where $K^{\prime} \subset K$. Now consider a risky asset $j^{\prime} \in K^{\prime}$, whose dividend stream is identical to the dividend stream of another risky asset $j \in K-K^{\prime}$, but, being in $K^{\prime}$ is not subject to sentiment. Assuming that the fund itself is subject to noise trader sentiment, but the underlying assets are not, we can think of asset $j$ as a stylized publicly traded fund, and asset $j^{\prime}$ as the fund's underlying portfolio. From (6) and (7) we derive the price of $j^{\prime}$ as 


$$
p_{j, t}^{\prime}=\frac{\beta \phi_{j}}{1-\beta \phi_{j}} d_{j, t}-\frac{\gamma}{1-\beta \phi_{j}}\left(\frac{\sigma_{v_{j, w}}}{r}\right)
$$

Subtracting $p_{j, t}^{\prime}$ from $p_{j, t}$ yields an expression for the discount:

$$
p_{j, t}^{\prime}-p_{j, t}=\frac{\gamma \beta}{1-\beta \psi_{j}}\left(\frac{\sigma_{u_{j, \mu}}}{r}\right)-\frac{\beta}{1-\beta \psi_{j}} \mu \rho_{j, r^{*}}
$$

Taking the unconditional mean we are able to express the average discount:

$$
\overline{p_{j}^{\prime}-p_{j}}=\frac{\gamma \beta}{1-\beta \psi_{j}}\left(\frac{\sigma_{v_{j, w}}}{r}\right)
$$

Equations (9) and (10) embody an "answer" to the closed-end fund puzzle: discounts will vary inversely with sentiment. Assuming that the underlying assets of the fund are not subject to the same variation in sentiment, the discount on the fund will shrink when noise traders are bullish on the fund. If the innovation in noise trader sentiment covaries positively with the innovation in total wealth, the covariance terms in equations (9) and (10) will be positive. Thus, discounts on the fund may prevail even when noise traders are neither currently bearish nor bullish. In section 8.4 .1 , below, we examine the average discount of country funds.

Because sentiment is not directly observable, the sentiment model per se does not generally establish any readily testable implications. However, in the context of publicly traded fund pricing, the difference between the price of a fund and its NAV can serve as this proxy. Equation (9) suggests that the sentiment attached to each fund $j$ will be perfectly correlated with its discount. Under the hypothesis that sentiment is attached only to the price of the fund, any testable implication that applies to the level of sentiment equally applies to the discount. With this in mind, one implication can be derived from rearranging (9) and substituting into (7).

$$
E_{t}\left(R_{j, t+1}\right)=\gamma \sigma_{R_{j} W}-\gamma \frac{\sigma_{u_{j}, W}}{r}+\frac{1-\beta \psi_{j}}{\beta}\left(p_{j, t}^{\prime}-p_{j, t}\right)
$$

The expected return on the fund is a function of its discount. The relationship is positive, so long as $\psi_{j}$ is less than one, that is, as long as sentiment is meanreverting. If sentiment for a fund drives the discount, then the discount will predict future risk-adjusted returns. These issues are examined in sections 8.4.2 and 8.4.3, below

The difference in the unconditional variance of the fund and the net asset returns is given by

$$
\operatorname{Var}\left(R_{j}\right)-\operatorname{Var}\left(R_{j}^{\prime}\right)=\left[\frac{\beta}{1-\beta \psi_{j}}\right]^{2} \sigma_{u_{j}}^{2}+\left[\frac{1}{1-\beta \psi_{j}}\right]\left[\frac{\beta}{1-\psi_{j}}\right] \sigma_{u_{j} v_{j}}
$$

The model predicts that the fund will exhibit more variability than the underlying assets so long as the shock to fundamentals does not covary excessively 
negatively with the shock to investor sentiment. We look at this in section 8.4.4.

From (6), the innovation in wealth is given as a weighted average of the innovations to fundamentals and sentiment:

$$
\begin{gathered}
W_{t}-E_{t-1} W_{t}=\left[\left(\boldsymbol{P}_{t}+D_{t}\right)-E_{t-1}\left(\boldsymbol{P}_{t}+\boldsymbol{D}_{t}\right)\right] \iota= \\
\sum_{k \in K} \frac{1}{1-\beta \phi_{k}} v_{k, t}+\sum_{k \in K^{\prime}} \frac{\beta}{1-\beta \psi_{k}} u_{k, t} .
\end{gathered}
$$

Using (12), we can express the covariance term in (9) as

$$
\begin{aligned}
\sigma_{u_{j} W} & =\left(\sum_{k \in K} \frac{1}{1-\beta \phi_{k}} \sigma_{z^{d}, z^{\rho}}\right)+\left(\sum_{k \in K^{\prime}} \frac{\beta}{1-\beta \psi_{k}} \sigma_{z^{\rho}}^{2}\right) \\
& +\left(\frac{1}{1-\beta \phi_{j}}\right)^{2} \sigma^{2} \varepsilon_{j}^{d}+\left(\frac{\beta}{1-\beta \psi_{j}}\right)^{2} \sigma^{2} \varepsilon_{j}^{\rho} .
\end{aligned}
$$

For the sentiment attached to any risky asset, or fund, $j$ to covary appreciably with wealth when $K$ is large, one of two conditions must be imposed on the behavior of noise traders. Specifically, either some component of the innovation in noise trader sentiment on fund $j$ covaries with the systematic variation in fundamentals, so that the first term in (13) is nontrivial; or the set of assets subject to common variation in noise trader sentiment, $K-K^{\prime}$, is large relative to $K$, so that the second term in equation (13) is nontrivial. Since publicly traded funds make up a small portion of all risky assets, for the second condition to hold, the systematic component in the innovation in sentiment must also be present in other risky assets besides being present in the funds. These two conditions lead to testable implications. First, the innovations in the discounts on funds will be correlated with innovations in the systematic component of fundamentals. Second, the innovations in the discounts of country funds will share a common component across the funds. Third, there will be other risky assets, besides the funds, whose prices rise independently of fundamentals when discounts on the funds narrow. A natural candidate for such an asset is one whose clientele is the same as the funds. We examine these issues in sections 8.4.5 and 8.5.1.

A specification for the innovations in fund discounts can be derived using the difference in returns between the fund and the net assets:

$$
R_{j, t+1}-R_{j, t+1}^{\prime}=\left(\sigma_{R_{j} W}-\sigma_{R^{\prime}, W}\right)-\mu \rho_{j, t}+\frac{\beta}{1-\beta \psi_{j}} u_{j, t+1} .
$$

Equation (14) says that the difference in realized returns between the fund and the net assets is due to shocks to investor sentiment. Equation (14) is a useful analytic tool in the context of the model because it implies that any variables which help to explain (are correlated with) the contemporaneous difference between the return on the fund and its assets, after controlling for the predictive 
power of the discount, will be variables correlated with either idiosyncratic or systematic variation in noise-trader misperceptions. Empirical versions of equation (14) are examined in section 8.5.2.

\subsection{Sample Data and Variable Definitions}

\subsubsection{The Sample}

The country funds used in our empirical work consist of the thirty-five single-country publicly traded funds which were covered in Barron's publicly traded funds column from January 1985 through January 1993, inclusive, and for which at least nine months of price data exist within that period. Table 8.1 provides the names of the country funds along with the date of their respective IPOs. Table 8.2 presents some summary statistics on the sample of country funds, and compares them with similar statistics for a sample of publicly traded domestic-equity funds, as well as a random sample of firms with market capitalizations comparable to that of the country funds. The sample of domestic-equity funds is taken from the list of "general equity funds" in Barron's. It includes the oldest and most well known domestic-equity funds. The samples of operating firms are random samples drawn from the third and fourth market-capitalization quintiles of firms in Standard \& Poor's Industrial Compustat Tape (the first quintile being the smallest firms).

The market capitalization of the country funds is on average smaller than that of the domestic-equity funds. This reflects, possibly, the older average age of the domestic-equity funds. Institutional ownership, measured as the fraction of shares owned by institutions, is smaller for the domestic-equity funds than for the country funds. However, both types of funds have much lower institutional ownership than operating firms with comparable levels of market capitalization. A common explanation for the lower participation of institutions in publicly traded funds is that institutional portfolio managers would rather not have to worry about justifying why they hold another managed fund and thus incur two management fees, one implicit and the other explicit. Table 8.2 suggests that individual investors are the clientele of country funds.

One difference between country funds and domestic-equity funds is that country funds may invest in stock markets which otherwise restrict international investment. ${ }^{9}$ A government contemplating opening its markets to U.S. investors may choose to admit a U.S.-based country fund as a means of limiting

9. Another difference between country funds and domestic-equity funds is that a host government may withhold taxes upon distributions to country fund shareholders. With reciprocal agreements between the host government and the U.S. government, the U.S. shareholder will include the withheld taxes as a foreign tax credit against U.S. taxes. In the absence of reciprocal agreements, however, the shareholder may be doubly taxed. The latter may have the effect of depressing the fund's price below its NAV in the presence of cross-border investment restrictions. 
Table 8.1

Sample of Closed-End Country Funds (dates of initial public offerings and dates of initial time-series observations)

\begin{tabular}{|c|c|c|}
\hline Country Fund (CODE) & $\begin{array}{c}\text { Date of } \\
\text { Initial Public } \\
\text { Offering (IPO) }\end{array}$ & $\begin{array}{c}\text { Date of } \\
\text { Initial Time-Series } \\
\text { Observations }\end{array}$ \\
\hline Austria (AUS) & $9-21-89$ & $10-6-89$ \\
\hline Brazil (BRZ) & $3-31-88$ & $4-15-88$ \\
\hline Brazil Equity (BRE) & 4-3-92 & 4-10-92 \\
\hline Chile (CHL) & $9-26-89$ & $10-20-89$ \\
\hline Emerging Germany (EMG) & $3-29-90$ & $4-20-90$ \\
\hline Emerging Mexico (EMX) & $10-2-90$ & $10-12-90$ \\
\hline First Australia (FAS) & $12-12-85$ & 1-3-86 \\
\hline First Iberian (FIB) & 4-3-88 & $4-22-88$ \\
\hline First Philippine (FPH) & $11-8-89$ & $12-1-89$ \\
\hline France Growth (FRG) & $5-10-90$ & $7-27-90$ \\
\hline Future Germany (FTG) & $2-27-90$ & $3-9-90$ \\
\hline Germany (GER) & $7-18-86$ & $8-22-86$ \\
\hline Growth Fund of Spain (GSP) & $2-14-90$ & $3-9-90$ \\
\hline Helvetia (Swiss) (SWH) & $8-19-87$ & $8-28-87$ \\
\hline India Growth (ING) & $8-12-88$ & $8-26-88$ \\
\hline Indonesia (IND) & $3-1-90$ & $3-16-90$ \\
\hline Irish Investment (IRE) & $3-3-90$ & $4-13-90$ \\
\hline Italy (ITL) & $2-26-86$ & $4-4-86$ \\
\hline Jakarta Growth (JKG) & $4-16-90$ & $4-20-90$ \\
\hline Japan OTC (JPO) & $3-14-90$ & $3-30-90$ \\
\hline Korea $(\mathrm{KOR})$ & $8-22-84$ & $1-4-85$ \\
\hline Korean Investment (KIN) & $2-18-92$ & $3-13-92$ \\
\hline Malaysia (MLY) & $5-8-87$ & $6-5-87$ \\
\hline Mexico Equity and Income (MEI) & $8-14-90$ & $9-7-90$ \\
\hline Mexico (MEX) & $6-3-81$ & $1-3-86$ \\
\hline New Germany (NGR) & $1-24-90$ & $2-9-90$ \\
\hline Portugal (PTG) & $11-1-89$ & $11-17-89$ \\
\hline ROC Taiwan (ROC) & $5-19-89$ & $5-19-89$ \\
\hline Singapore (SNG) & $7-24-90$ & $8-3-90$ \\
\hline Spain (SPN) & $6-21-88$ & $7-15-88$ \\
\hline Taiwan (TAW) & $12-23-86$ & $2-13-87$ \\
\hline Thai (THA) & $2-17-88$ & $2-26-88$ \\
\hline Thai Capital (THC) & $5-22-90$ & 6-8-90 \\
\hline Turkish Investment (TRK) & $12-5-89$ & $12-15-89$ \\
\hline United Kingdom (UKF) & $8-6-87$ & 8-7-87 \\
\hline
\end{tabular}

Source: IPO dates are from Moody's Financial Manual.

such an opening to professional managers buying a fixed amount of shares. Typically, a fund is admitted prior to, or instead of, the introduction of American depository receipts (ADRs) or a full opening. Table 8.2 shows that country funds investing in unrestricted foreign markets tend to have smaller institutional ownership than funds investing in countries that restrict international 
Market Capitalization and Institutional Holdings of Country Funds ${ }^{\mathrm{a}}$

\begin{tabular}{lcccc}
\hline & $\begin{array}{c}\text { Number of } \\
\text { Firms/Funds } \\
\text { in Sample }\end{array}$ & $\begin{array}{c}\text { Average } \\
\text { Market } \\
\text { Capitalization } \\
\text { (\$ million) }\end{array}$ & $\begin{array}{c}\text { Average } \\
\text { Number of } \\
\text { Institutional } \\
\text { Owners }\end{array}$ & $\begin{array}{c}\text { Average } \\
\text { Percentage of } \\
\text { Shares Held by } \\
\text { Institutions }\end{array}$ \\
\hline Country funds & 35 & 110.92 & 18 & 14 \\
$\quad$ Unrestricted & 21 & 87.13 & 16 & 11 \\
$\quad$ Restricted & 14 & 146.6 & 21 & 18 \\
Domestic funds & 19 & 402.4 & 23 & 6 \\
Third quintile Compustat firms & 40 & 57.13 & 22 & 25 \\
Fourth quintile Compustat & & & & 40 \\
$\quad$ firms & 43 & 236.13 & 60 & 40 \\
\hline
\end{tabular}

Source: Data on market capitalization and institutional holdings is from Standard \& Poor's Stock Guide for December 1992.

aSummary statistics for the sample of thirty-five country funds are compared to a sample of domestic equity funds and to a sample of operating firms whose average capitalization is comparable to the country funds. The sample of domestic equity funds is taken from the list of "general equity funds" in Barron's. The samples of operating firms are random samples drawn from the third and fourth quintiles in Standard \& Poor's Industrial Compustat Tape, on the basis of total market capitalization (first quintile being the smallest firms). See the text for a description of the classification of country funds into the unrestricted and restricted samples.

investment in their respective equity markets. ${ }^{10}$ Apparently, an institution can justify investing in particular foreign markets, and incurring an additional management fee, if the country fund is the only avenue by which such diversification is possible.

\subsubsection{Variable Definitions}

Weekly data on price and reported NAV of the funds was collected from Barron's and the funds themselves. ${ }^{11}$ With the exception of the India Growth Fund (ING), which is excluded from the regressions in the empirical sections below, a complete time series of NAVs was obtained for each of the thirty-five funds. Barron's reports either the Friday or Thursday closing price in New York. The funds compute their reported NAVs by translating the local currency price of the assets at the local market close into U.S. dollars. The translation to dollars, however, is not uniform as some funds use the exchange rate at the local market close, whereas others use an afternoon fix in New York. Since foreign markets close on a given day prior to the close in New York, prices and NAVs will be only approximately synchronous. Constructed financial returns

10. Our classifications, "restricted" and "unrestricted," are based on the classification given in the International Finance Corporation's Emerging Markets Handbook. The IFC classifies countries into five categories according to their degree of openness: "free," "relatively free," "authorized investors," "special classes of shares," and "closed." We placed all countries represented in our sample which are not classified as emerging markets in the "unrestricted" category, along with those classified as "free" by the IFC. All others were placed in the restricted category.

11. The integrity of the data was ensured by checking all outliers and missing observations against the data bases kept at the offices of the fund managers or administrators. 
were adjusted for splits and in-kind distributions using the data in Standard and Poor's Dividend Record..$^{12}$ Table 8.3 provides a description of the variables used in the later empirical analysis.

We compute funds $i$ 's "discount" as the natural logarithm of the ratio of the fund's net asset value per share (NAV) to its share price (FND). Specifically,

$$
D I S C_{i, t}=\ln \left(N A V_{i, r} / F N D_{i, t}\right) \text {. }
$$

The continuously compounded return on the fund itself, $R F N D_{i, t+1}$, and on the net assets of the fund, $R N A V_{i, t+1}$, are defined as follows:

$$
\begin{aligned}
& R F N D_{i, t+1}=\ln \left(\frac{\mathrm{FND}_{i, t+1}+D S T_{i, t+1}}{\mathrm{FND}_{i, t}}\right), \\
& R N A V_{i, t+1}=\ln \left(\frac{N A V_{i, t+1}+D S T_{i, t+1}}{N A V_{i, t}}\right),
\end{aligned}
$$

where $F N D_{i, t+1}$ and $N A V_{i, t+1}$ are the price and the net asset value (per share) of the $i$ th fund at the end of week $t+1$; and $D S T_{i, t+1}$ is the distribution during week $t+1$, assumed to take place at the end of the week. Cumulative returns for horizons of four and thirteen weeks are defined by adding the individual weekly returns over the relevant horizons.

Observe that if the dividend distribution is zero or very small, the change in the discount, $\Delta D I S C_{i, t+1}=D I S C_{i, t+1}-D I S C_{i, t}$, reflects the difference between the continuously compounded weekly return on net assets, RNAV, and the continuously compounded weekly return on the fund itself, $R F N D: \triangle D I S C_{i, t+1}=$ $R N A V_{i, t+1}-R F N D_{i, t+1}$.

\subsection{The Time-Series Behavior of the Discount}

This section investigates the time-series behavior of the discount or premium on country funds. We begin with an examination of the average discount over the full sample, as well as its behavior during the first six months after the initial public offering of the fund. We continue with standard nonstationarity tests of country fund discounts, which lead us to examine the predictive power

12. Pursuant to the Investment Company Act, the funds make two kinds of distributions: an income distribution based on portfolio earnings net of expenses, and a capital gains distribution based on realized portfolio appreciation. The shareholder is taxed on capital gains distributions at his relevant capital gains tax rate. Income distributions are taxed at the regular income tax rate. Whereas the Internal Revenue Code requires the funds to distribute at least 98 percent of their income in order to avoid an excise tax, the funds may choose to retain capital gains. Most funds elect to make capital gains distributions, rather than retain them, because corporate tax rates on capital gains exceed individual rates. If the fund does choose to retain portfolio capital gains and pay taxes on them, the taxpaying shareholder can earn a tax credit equal to the proportionate amount of the share of federal taxes paid by the fund on the shareholder's behalf and then increase the year-end cost basis of the shares by the retained amount. This is because the shareholder is deemed to have reinvested the amount retained by the fund net of tax (see Fredman and Scott 1991). 
Table 8.3 Variable Definitions and Construction

$F N D_{i, 1} \quad$ Dollar price of country fund $i$ at the end of week $t$. All prices are recorded at Friday's market close in New York with the following exceptions: the Brazil (BRZ), Brazil Equity (BRE), Emerging Mexico (EMX), Mexico Equity and Income (MEI), Mexico (MEX), Singapore (SNG), and Taiwan (TAW) fund prices are recorded at Thursday's market close; the India Growth Fund (ING) prices are recorded at the Wednesday close. If the reporting day is a New York holiday, the previous day's New York closing prices are used.

$N A V_{i, \ell} \quad$ Dollar net asset value of fund $i$ at the end of week $t$. The NAV is computed by the fund itself using the local-currency prices of the underlying assets recorded at Friday's local market close and the Friday afternoon fix for exchange rates in New York with the following exceptions: the BRZ, BER, EMX, MEI, MEX, SNG, and TAW funds construct the NAV using prices at Thursday's local market close, and Thursday afternoon's New York exchange rate. The ING fund uses Wednesday's prices and exchange rates. If the reporting day is a New York holiday, the previous day's local closing prices and exchange rates are used.

$R E X_{i, t+1} \quad \ln \left(E X_{i, t+1} / E X_{i, e}\right)$, the continuously compounded weekly dollar return on holding a unit of the currency of the country represented by fund ${ }_{i} . E X_{i, t}$ represents the exchange rate at 3:00 P.M. in New York (expressed in dollars per foreign currency unit) at the end of week $t$, where the day marking the end of the week matches the day on which $F N D_{i, t}$ and $N A V_{i, t}$ are recorded. Source: Federal Reserve Bank of New York for the currencies of Australia, Austria, France, Germany, Ireland, Italy, Japan, Spain, Switzerland, and the United Kingdom (all bids). Remaining exchange rates come from Banque de Generale through Data Resources (DRI), and reflect the middle of the bid-ask spread.

$R F S T_{l, t+1} \quad \ln \left(F S T_{i, t+1} / F S T_{i, t}\right)$, the weekly return (excluding dividends) on the host country's aggregate stock market in local currency units. $F S T_{i, t}$ is the host country's aggregate stock market price index in local currency at the end of week $t$, matching the day that FND and NAV are recorded. Source: Morgan Stanley Capital International (MSCI) through DRI.

$R S P_{i, t+1} \quad \ln \left(S P 500_{t+1} / S P 500\right)$, the weekly return on the Standard and Poor's 500 (excluding dividends), computed separately for each fund to match the same calendar horizon as RFND and RNAV. Source: DRI.

$R S M L_{i, r+1} \quad \ln \left(R 2000_{t+1} / R 2000_{t}\right)$, the weekly return on the Russell-2000 index of small capitalization stocks (excluding dividends), computed separately for each fund to match the same calendar horizon as RFND and RNAV. Source: DRI.

$R W R D_{i, t+1} \ln \left(W O R L D_{t+1} / W O R L D_{t}\right)$, the weekly return on the world stock market in dollars (excluding dividends), computed separately for each fund to match the same calendar horizon as RFND and RNAV. Source: MSCI through DRI.

of the discounts. Finally, we present evidence that, consistent with the predictions of the noise-trading model, a large fraction of the variation in individual country fund discounts is common across the funds.

\subsubsection{Average Discounts and Aftermarket Performance of Country Funds}

The first column of Table 8.4 presents the cross-sectional average of timeseries means of the discount of all thirty-five funds over the sample period. 


\begin{tabular}{|c|c|c|c|c|c|c|c|c|c|c|}
\hline & \multirow{2}{*}{$\begin{array}{l}\text { Average } \\
\text { Premium/ } \\
\text { Discount }\end{array}$} & \multirow{2}{*}{$\begin{array}{c}\text { Mean } \\
\text { Underwriter's } \\
\text { Premium }\end{array}$} & \multirow{2}{*}{$\begin{array}{c}\text { Mean } \\
\text { Premium } \\
\text { at First } \\
\text { Observation }\end{array}$} & \multicolumn{6}{|c|}{ Mean Premium at: } & \multirow{2}{*}{$\begin{array}{c}\text { Average } \\
\text { Premium/ } \\
\text { Discount } \\
\text { (not including weeks } \\
0 \text { to }+24 \text { ) }\end{array}$} \\
\hline & & & & +4 & +8 & +12 & +16 & +20 & +24 & \\
\hline $\begin{array}{l}\text { Country funds } \\
\text { (35) }\end{array}$ & $\begin{array}{c}-0.031 \\
(0.025)\end{array}$ & 0.0755 & $\begin{array}{c}0.142 \\
(0.049)\end{array}$ & $\begin{array}{c}0.061 \\
(0.053)\end{array}$ & $\begin{array}{c}0.031 \\
(0.049)\end{array}$ & $\begin{array}{c}-0.002 \\
(0.038)\end{array}$ & $\begin{array}{c}-0.044 \\
(0.037)\end{array}$ & $\begin{array}{c}-0.061 \\
(0.036)\end{array}$ & $\begin{array}{c}-0.070 \\
(0.045)\end{array}$ & $\begin{array}{c}-0.056 \\
(0.022)\end{array}$ \\
\hline $\begin{array}{l}\text { Unrestricted } \\
\text { (21) }\end{array}$ & $\begin{array}{c}-0.067 \\
(0.019)\end{array}$ & 0.0767 & $\begin{array}{c}0.074 \\
(0.034)\end{array}$ & $\begin{array}{c}-0.019 \\
(0.037)\end{array}$ & $\begin{array}{c}-0.023 \\
(0.041)\end{array}$ & $\begin{array}{c}-0.047 \\
(0.035)\end{array}$ & $\begin{array}{c}-0.098 \\
(0.031)\end{array}$ & $\begin{array}{c}-0.117 \\
(0.022)\end{array}$ & $\begin{array}{c}-0.139 \\
(0.021)\end{array}$ & $\begin{array}{c}-0.091 \\
(0.019)\end{array}$ \\
\hline $\begin{array}{l}\text { Restricted } \\
\text { (14) }\end{array}$ & $\begin{array}{c}0.020 \\
(0.048)\end{array}$ & 0.0737 & $\begin{array}{c}0.244 \\
(0.106)\end{array}$ & $\begin{array}{c}0.180 \\
(0.113)\end{array}$ & $\begin{array}{c}0.112 \\
(0.055)\end{array}$ & $\begin{array}{c}0.112 \\
(0.057)\end{array}$ & $\begin{array}{c}0.081 \\
(0.055)\end{array}$ & $\begin{array}{c}0.058 \\
(0.044)\end{array}$ & $\begin{array}{c}0.068 \\
(0.047)\end{array}$ & $\begin{array}{r}-0.007 \\
(0.044)\end{array}$ \\
\hline
\end{tabular}

a'The table reports the cross-sectional means and standard errors of the premium/discount on the first date for which the fund reports a net asset value and at subsequent four-week intervals. In all but two cases (MEX and KOR) the first NAV observation date corresponds to the first sample observation reported in table 8.1. The first NAV observation date usually follows the IPO by two to three weeks. The table applies the convention that premia are denoted as positive while discounts are denoted as negative. See the text for a description of the classification of unrestricted and restricted funds. 
Although the average discount is not significantly different from zero, separating the funds into those pertaining to countries with restricted and unrestricted equity markets reveals a difference between the two groups. The average discount on funds whose host markets are unrestricted is almost 7 percent and significantly different from zero $(t$-statistic $=3.53$ ), while the average discount on funds associated with restricted host markets is not significant. This evidence is consistent with theoretical models illustrating that international investment barriers can cause prices of assets of equal risk to differ across countries. All else equal, a binding restriction will raise the price-NAV ratio above the level prevailing in the absence of such restrictions (Errunza and Losq 1985; Eun and Janakiramanan 1986). ${ }^{13}$

Table 8.4 also examines the aftermarket performance of the country funds relative to their underlying assets. One prediction of the noise-trading model is that a new fund will be issued only when sentiment for the fund is high. After an IPO, the fund's organizers invest the proceeds, net of underwriting fees, in accordance with the fund's investment objective. Because the amount of the offering exceeds the proceeds which constitute the initial NAV of the fund, the fund is issued at a premium. This premium is a derivative of the underwriting fees and start-up costs. A successful offering implies that some investors are willing to pay a premium for the cash that the fund is holding after the offering. The fact that some investors are willing to pay a premium can also be taken as evidence of bullish noise trader sentiment for a country. Naturally, organizers will try to time issuance to coincide with this bullishness. If the noise-trading story is true and sentiment is mean-reverting, following an IPO the original high premium ought to deteriorate. A deterioration would occur even if, with cross-border restrictions, the average discount is small or if on average a premium prevails. Table 8.4 confirms these predictions.

Table 8.4 shows that country funds are issued with an underwriter's premium of about 7.5 percent. Market premia appear to be larger, however. Our first NAV data are available on average about two weeks after the IPO. They show that funds associated with restricted markets trade, at that time, at premia of almost 25 percent whereas funds associated with unrestricted markets trade at a premium of roughly 7.4 percent. Following the first price-NAV observation, the premia begin to erode. After twenty-four weeks, the premium on restricted funds falls to 6.8 percent from the original 24.4 percent, and the premium on unrestricted funds becomes -13.9 percent (a discount) from the original 7.4 percent. Recall that the change in the premium can be approximately interpreted as the difference between the cumulative returns on the fund and on the NAV. Accordingly, investors who buy an unrestricted country's fund in the

13. Bonser-Neal, Brauer, Neal, and Wheatley (1990) demonstrate that a relation exists for all but one of the five countries examined, between announcements of changes in investment restrictions and changes in discounts and premia. Bonser-Neal et al. confirm, however, that changes in cross-border restrictions are unable to account for much, if not all, of the time-variation in discounts and premia. 
immediate aftermarket and sell it twenty-four weeks later experience a negative return of 21.3 percent relative to the NAV, while holders of a restricted country's fund experience a loss of 17.6 percent relative to the NAV. Assuming cross-sectional independence, both of these average cumulative returns are significantly different from zero. Moreover, a nonparametric U-test does not reject the hypothesis that the average twenty-four-week returns are the same across the two groups of funds. ${ }^{14}$ Finally, the last column of table 8.4 shows that if the first twenty-four weeks are omitted from each fund's time series, the average discount for the full sample is almost 6 percent and significant, while the average discount for the unrestricted sample is 9 percent and also significant. The evidence presented in table 8.4 suggests that after taking account of the effects of cross-border restrictions, the aftermarket performance of country funds adheres to the stylized facts derived for the domestic equity funds: in the long run a discount prevails.

\subsubsection{Stationarity Tests ${ }^{15}$}

If all publicly traded funds are ultimately liquidated, discounts are in the long run stationary. Over short time intervals, however, discounts could be nonstationary. Discount stationarity is relevant in the context of the noise-trader model because the discount reflects the sentiment attached to a particular country fund. If sentiment is mean-reverting, and variation in sentiment drives the discount, then discounts should also be mean-reverting. Alternatively, if under cross-border segmentation, variation in discounts is driven by changes in the ratio of the domestic price of risk to the foreign price of risk, then the price of a fund might have no inherent tendency to revert to the market price of the underlying assets, and the discount could be nonstationary.

To test the hypothesis of nonstationarity, we employ Stock and Watson's (1988) unit root test twice, for the model with and without a time trend. We also perform the test using either one or eight autoregressive lags. Table 8.5 presents the results. The hypothesis of nonstationarity is rejected for most of the country funds. When the number of autoregressive lags is one, the hypothesis is rejected at the 10 percent level for twenty-three funds in the model with a time trend, and for twenty-three funds in the model without a time trend.

14. Weiss (1989) examines aftermarket prices of both domestic- and foreign-equity fund IPOs. Although she finds that the mean premium for a sample of foreign stock funds (country funds and internationally diversified funds) is significantly negative ( -11.42 percent) six months following an IPO, unlike the domestic-equity funds examined, the cumulative returns on the international funds over six months are not statistically different from zero. Because Weiss evaluates an earlier period (1985-87), her sample of fifteen foreign funds is relatively small, and this may explain her negative results. Peavey (1990) examines IPOs and aftermarket performance of publicly traded funds between 1986 and 1987 , including five country funds. His tests make no reference to fund returns relative to NAV returns, yet he finds that T-bill- and market-adjusted returns are significantly negative in the aftermarket.

15. The tests in this section, as well as the regressions and tests in the rest of the paper, exclude the India Growth Fund (ING). We were unable to obtain an unbroken time series of NAVs for this fund. 


\begin{tabular}{|c|c|c|c|c|c|}
\hline \multirow[b]{3}{*}{ Fund } & \multirow[b]{3}{*}{$\begin{array}{l}\text { Time-Series } \\
\text { Observations }\end{array}$} & \multicolumn{4}{|c|}{ Stock-Watson Test Statistic } \\
\hline & & \multicolumn{2}{|c|}{ Autoregressive Corrections $=1$} & \multicolumn{2}{|c|}{ Autoregressive Corrections $=8$} \\
\hline & & $\begin{array}{l}\text { Time-Trend } \\
\text { Filtered }\end{array}$ & $\begin{array}{l}\text { Not Time-Trend } \\
\text { Filtered }\end{array}$ & $\begin{array}{l}\text { Time-Trend } \\
\text { Filtered }\end{array}$ & $\begin{array}{c}\text { Not Time-Trend } \\
\text { Filtered }\end{array}$ \\
\hline AUS & 174 & -2.37 & -2.39 & -2.70 & $-2.93 * *$ \\
\hline BRZ & 251 & $-3.25 *$ & -2.05 & -2.04 & -1.19 \\
\hline BRE & 43 & -3.05 & -2.21 & -2.43 & -1.94 \\
\hline $\mathrm{CHL}$ & 172 & -2.50 & $-2.70^{*}$ & -1.59 & -2.08 \\
\hline EMG & 146 & $-4.48 * * *$ & $-4.01 * * *$ & $-3.35^{*}$ & -2.55 \\
\hline EMX & 121 & $-4.47 * * *$ & $-2.97 * *$ & $-3.55^{* *}$ & -2.33 \\
\hline FAS & 370 & $-4.37 * * *$ & $-4.28^{* * *}$ & $-4.00^{* * *}$ & $-3.72 * * *$ \\
\hline FIB & 250 & -2.70 & -2.54 & -2.43 & -2.36 \\
\hline FPH & 167 & -2.71 & $-3.00 * *$ & $-4.36^{* * *}$ & $-4.66 * * *$ \\
\hline FRG & 132 & $-5.19 * * *$ & $-3.97 * * *$ & -2.22 & -1.55 \\
\hline FTG & 152 & $-4.46 * * *$ & $-4.22 * * *$ & $-3.85^{* *}$ & $-3,49 * * *$ \\
\hline GER & 337 & $-3.54 * *$ & $-3.25 * *$ & $-3.14^{*}$ & $-2.93 * *$ \\
\hline GSP & 152 & $-3.35^{*}$ & $-3.19 * *$ & -2.77 & -2.38 \\
\hline SWH & 284 & $-4.40^{* * *}$ & $-3.59 * * *$ & $-3.56 * *$ & $-3.00 * *$ \\
\hline ING & 323 & - & - & - & - \\
\hline IND & 151 & $-3.88 * *$ & $-2.93 * *$ & $-3.29 *$ & -2.02 \\
\hline IRE & 147 & $-4.25^{* * *}$ & $-3.31 * *$ & -3.00 & -1.82 \\
\hline ITL & 357 & $-4.10 * * *$ & $-3.61 * * *$ & $-4.09 * * *$ & $-3.49 * * *$ \\
\hline JKG & 145 & $-3.33^{*}$ & -2.36 & $-3.72 * *$ & -1.95 \\
\hline JPO & 148 & -2.76 & -2.20 & $-3.72 * *$ & -2.41 \\
\hline KOR & 422 & -2.69 & -2.43 & -3.04 & $-2.74^{*}$ \\
\hline KIN & 47 & -1.43 & -1.81 & -2.22 & $-2.77 *$ \\
\hline MLY & 296 & -3.00 & $-3.02^{* *}$ & $-3.43 * *$ & $-3.42^{* *}$ \\
\hline MEI & 126 & $-4.27 * * *$ & $-2.64^{*}$ & $-3.97 * * *$ & -2.33 \\
\hline $\mathrm{MEX}$ & 370 & $-4.97 * * *$ & $-3.87 * * *$ & $-3.70^{* *}$ & -2.54 \\
\hline NGR & 156 & $-4.82 * * *$ & $-5.12 * * *$ & -2.72 & $-2.87 * *$ \\
\hline PTG & 168 & -2.84 & $-2.93 * *$ & $-3.26^{*}$ & $-3.44 * * *$ \\
\hline ROC & 194 & $-3.53 * *$ & $-3.07 * *$ & $-4.42 * * *$ & $-3.60 * * *$ \\
\hline SNG & 131 & $-4.24 * * *$ & -2.07 & -2.99 & -2.24 \\
\hline SPN & 238 & -1.82 & -1.73 & -2.40 & -2.30 \\
\hline TAW & 312 & $-3.43 * *$ & $-3.42 * *$ & $-4.21 * * *$ & $-3.73 * * *$ \\
\hline THA & 258 & $-3.39 *$ & $-2.58 *$ & $-3.28^{*}$ & -2.27 \\
\hline $\mathrm{THC}$ & 139 & $-4.18^{* * *}$ & $-4.22^{* * *}$ & $-3.22^{*}$ & $-3.22 * *$ \\
\hline TRK & 164 & $-3.22^{*}$ & -1.55 & -2.15 & -1.23 \\
\hline UKF & 287 & $-7.22^{* * *}$ & $-4.49 * * *$ & $-3.80 * *$ & $2.66^{*}$ \\
\hline \multicolumn{6}{|c|}{$\begin{array}{l}\text { Number } \\
\text { significant }\end{array}$} \\
\hline
\end{tabular}

${ }^{a}$ The table reports the results from applying Stock and Watson's (1988) unit-root test (for a univariate time-series) to the country fund discount data. The test requires first transforming each fund's discount by taking first differences. The first-differenced series are then passed through two separate filters. The first filter removes autoregressive dependence of order 1 or 8 (the "autocorrelation 
Table 8.5

(continued)

correction") as well as a time trend. The second filter makes the autocorrelation correction of order 1 or 8 but does not remove the time trend. Each filtered series $F \Delta D I S C_{i, i}$ is then regressed on the lagged value of the discount:

$$
F \Delta D I S C_{i, t}=-b_{i} D I S C_{i, t-1}+e_{i, r}
$$

The table reports (for each fund) the test statistics associated with the null hypothesis that $b_{i}$ is less than or equal to zero (a unit root). The test statistics are distributed under the null according to the empirical distributions given in Stock and Watson 1988.

*Test statistic is significant at the 10 percent level. ${ }^{* *}$ Test statistic is significant at the 5 percent level. ***Test statistic is significant at the 1 percent level.

When the number of autoregressive lags is eight, the hypothesis is rejected for twenty funds in the model with a time trend, and for sixteen funds in the model without. Assuming independence across the funds, and using the normal approximation to the binomial distribution, one can compute the probability that the above results were generated under the null hypothesis that all fund discounts are nonstationary. In all four cases, rejections occur at the 1 percent significance level.

In some funds, the hypothesis of nonstationarity is not rejected. In these exceptional cases, however, changes in the ratio of foreign to domestic price of risk in the context of cross-border investment restrictions are unlikely to be responsible for the failure to reject nonstationarity. Examination of table 8.5 reveals no special pattern across the restricted and unrestricted funds. The Emerging Mexico (EMG, First Philippine (FPH), Indonesia (IND), Mexico (MEX), Mexico Income and Equity (MEI), Taiwan (TAW), ROC Taiwan (ROC), Thai (THA), and Thai Capital (THC) funds generally reject nonstationarity of discounts even though they are associated with restricted capital markets. Meanwhile, the Austria (AUS), Japan OTC (JPO), Singapore (SNG), and Spain (SPN) funds fail to reject nonstationarity even though they invest in largely unrestricted markets.

The median first-order autoregressive coefficient across the thirty-five discounts of the country funds is $\mathbf{0 . 8 8 7}$, implying that an innovation in the discount has a half-life of roughly five weeks. Similarly, the average correlation between consecutive weekly discounts is approximately 0.854 , implying that the first-order autoregressive process can explain about 73 percent of discount variation. The correlation at four weeks is $0.57\left(R^{2}=0.32\right)$, and is substantially less than the one-month correlation (0.85) found by Pontiff (1991) using Lee, Shleifer, and Thaler's domestic-equity fund data.

\subsubsection{Do Fund Returns Vary Excessively?}

Sharpe and Sosin (1975), using quarterly data from 1966 to 1973 on eight domestic funds, find that the unconditional variance of the median fund's return is 36 percent greater than the variance of its net asset value return. Pontiff 
(1991), using Lee, Shleifer, and Thaler's data set, finds that return volatility is 73 percent greater than the volatility of the fund's assets. The relative variance of returns on the funds is important because it addresses the issue of excess volatility that noise traders, through the mechanism of public trading, may induce in the prices of traded assets. The fund's return is excessively volatile if $\operatorname{Var}(R F N D)>\operatorname{Var}(R N A V)$, or $\operatorname{Var}(\triangle D I S C)-2 \operatorname{Cov}(\triangle D I S C, R N A V)>0$. Following Pontiff (1991), to reduce skewness we computed the log variance ratio on each of the thirty-five country funds as the natural $\log$ of the ratio of the variance of the fund's return to the variance of the return on its assets. This ratio will be zero if the variance of a fund's return is equal to the variance of the NAV return. For our sample of funds we found the mean log variance to be 1.17 (standard error $=0.57$ ). The median ratio is 1.135 , implying that for the median fund (UKF), the variance of its return is more than three times greater than the variance of its net asset return. It is unlikely that a variance ratio of this magnitude could be attributable to bias in the variance estimates deriving from bid-ask spread bias.

\subsubsection{The Predictive Power of Discounts}

Mean reversion in the discounts, as demonstrated above, implies that the discount of a given country fund can predict a subsequent change in the discount. Moreover, since the change in a discount reflects (approximately) the difference between the returns on the fund and its assets, a larger premium predicts either (a) a smaller subsequent cumulative return on the fund, or (b) a larger cumulative return on the fund's assets, or (c) both a smaller return on the fund and a larger return on the NAV. In the context of the noise-trader model, the first case occurs when sentiment affects only the price of the fund, and the fund premium is perfectly positively correlated with that sentiment. In the second case, sentiment affects only the underlying assets, and the premium on the fund price is perfectly negatively correlated with that sentiment. In the third case, both the fund and the underlying assets are subject to sentiment, and the discount is a noisy measure of both sentiment on the fund and sentiment on the underlying assets. Thus, although from the level of the discount we can infer only the differential in sentiment between the country-fund and foreignmarket clienteles, the power of the discount in predicting fund returns (relative to its predictive power for the NAV returns) can be taken as an indication of the extent to which sentiment affects only the fund price.

The empirical literature on domestic-equity funds upholds that deep discounts are indicative of positive risk-adjusted returns. ${ }^{16}$ Although this empirical relation is well established for domestic-equity funds and has become pop-

16. Thompson (1978), using a sample of twenty-three (primarily NYSE) domestic-equity funds traded between 1940 and 1975 , demonstrates that risk-adjusted returns on portfolios of discounted fund shares outperformed the market. Richards, Fraser, and Groth (1980) and Anderson (1986), using a sample of diversified and specialized domestic-equity funds, derive optimal trading rules for earning excess rates of return. 
ularized (Malkiel 1990), to our knowledge no one has examined these empirical relations for country funds. ${ }^{17}$ To examine the predictive power of country fund discounts we ran regressions of the form

$$
\begin{gathered}
\sum_{n=1}^{N} R F N D_{t+n}=\alpha_{i}^{f}+\beta_{i}^{f} D I S C_{i, t}+\mathrm{e}_{i, t}^{f} \\
\sum_{n=1}^{N} R N A V_{t+n}=\alpha_{i}^{a}+\beta_{i}^{a} D I S C_{i, t}+\mathrm{e}_{i, t}^{a},
\end{gathered}
$$

where the $\alpha_{i}$ and $\beta_{i}$ are fund-specific intercepts and slope coefficients and $N$ denotes the cumulative return horizon. In table 8.6, we report the estimates of $\beta_{i}^{f}$ and $\beta_{i}^{a}$, as well as the adjusted $R^{2}$, for regressions using cumulative return horizons of one, four, and thirteen weeks. Panel $\mathrm{A}$ in table 8.6 shows that an increase in the discount is generally associated with a subsequent increase in the fund's return. As the return horizon increases from one week to thirteen weeks, the reversal in the fund price becomes progressively stronger, generating a larger regression coefficient between the cumulative return on the fund and the discount. Evidently, bid-ask bias or other measurement errors cannot account for the price reversal. ${ }^{18}$ The average adjusted $R^{2} \mathrm{~s}$ of the regressions are 0.053 for the one-week return horizon, 0.106 for the four-week horizon, and 0.179 for the thirteen-week horizon. The strong predictability of fund returns supports the hypothesis that sentiment is a component of the price of the fund.

High discounts are less successful at predicting low NAV returns. Few regression coefficients are negative and significant in panel $\mathrm{B}$ of table 8.6 and the $R^{2} \mathrm{~s}$ are much lower, on average, than in panel A. The average adjusted $R^{2} \mathrm{~s}$ are $0.007,0.031$, and 0.084 for the one-, four-, and thirteen-week horizons, respectively. Nonetheless, most regression coefficients in panel B are negative, and for five funds (AUS, IND, JKG, ROC, TAW) the regression coefficients are generally negative and significant. Occasionally, therefore, discounts contain some information about future net asset value returns, implying that a small component of the discount reflects the sentiment of foreign investors which affects the price of the underlying assets. That is, the price of the fund captures fundamental information not captured by the NAV.

\subsubsection{Is There a Common Component in Country Fund Discounts?}

So far, we have analyzed individual country funds in isolation. We now examine comovement in country fund discounts. The noise-trader model sug-

17. Some commentators have argued that a country fund with a large premium may reflect the underpricing of the underlying assets due to unwarranted bearishness by the local investors. For example, see the discussion in Fredman and Scott (1991) concerning the views of Jon Woronoff in the International Fund Monitor, June 1990.

18. For the equations describing the thirteen-week cumulative returns on the country funds, we find that the coefficient on the discount is positive and significant at the 10 percent level or less for twenty-seven ( 79 percent) of the country funds. Using the normal approximation to the binomial distribution, and assuming cross-sectional independence, this result is associated with a $p$-value of less than 1 percent under the null hypothesis that no positive association exists between discounts and future returns on the fund. 
A. Cumulative Return on the Fund Is Regressed on the Discount

\begin{tabular}{|c|c|c|c|c|c|c|}
\hline \multirow[b]{2}{*}{ Fund } & \multicolumn{2}{|c|}{$\begin{array}{c}\text { Return Horizon }= \\
1 \text { week }\end{array}$} & \multicolumn{2}{|c|}{$\begin{array}{c}\text { Return Horizon }= \\
4 \text { weeks }\end{array}$} & \multicolumn{2}{|c|}{$\begin{array}{c}\text { Return Horizon }= \\
13 \text { weeks }\end{array}$} \\
\hline & $\beta_{i}^{\prime}$ & Adjusted $R^{2}$ & $\beta_{i}$ & Adjusted $R^{2}$ & $\beta_{i}^{\prime}$ & Adjusted $R^{2}$ \\
\hline AUS & 0.033 & 0.00 & 0.063 & -0.00 & 0.173 & 0.01 \\
\hline BRZ & 0.027 & 0.01 & 0.033 & 0.00 & 0.104 & 0.01 \\
\hline BRE & $0.249^{* *}$ & 0.10 & $0.849 * * *$ & 0.41 & $0.823^{* * *}$ & 0.14 \\
\hline CHL & $0.129 * * *$ & 0.06 & $0.340^{* * *}$ & 0.12 & $0.934^{* * *}$ & 0.27 \\
\hline EGR & $0.289^{* * *}$ & 0.10 & $0.711 * * *$ & 0.20 & $0.938 * * *$ & 0.23 \\
\hline $\mathrm{EMX}$ & $0.303 * * *$ & 0.09 & $0.592 * * *$ & 0.11 & $1.432 * *$ & 0.16 \\
\hline FAS & $0.117^{* * *}$ & 0.04 & $0.272 * *$ & 0.06 & $0.517^{* *}$ & 0.08 \\
\hline FIB & $0.057^{* * *}$ & 0.02 & $0.214^{* *}$ & 0.07 & $0.405^{*}$ & 0.10 \\
\hline FPH & $0.076^{* * *}$ & 0.04 & $0.237 * *$ & 0.13 & $0.828^{* * *}$ & 0.47 \\
\hline FRG & $0.584 * * *$ & 0.28 & $1.055^{* * *}$ & 0.40 & $1.140 * * *$ & 0.36 \\
\hline FTG & $0.330 * * *$ & 0.13 & $0.853 * * *$ & 0.26 & $1.107 * * *$ & 0.34 \\
\hline GER & $0.064^{*}$ & 0.01 & 0.170 & 0.03 & $0.400^{*}$ & 0.06 \\
\hline GSP & $0.225 * * *$ & 0.08 & $0.578 * * *$ & 0.12 & $1.084 * * *$ & 0.16 \\
\hline SWH & $0.129 * * *$ & 0.05 & $0.283^{* * *}$ & 0.07 & $0.655 * * *$ & 0.16 \\
\hline ING & - & - & 一 & - & - & - \\
\hline IND & $0.100^{*}$ & 0.03 & 0.160 & 0.03 & 0.004 & -0.01 \\
\hline IRE & $0.251 * * *$ & 0.16 & $0.558 * * *$ & 0.23 & $1.067^{* * *}$ & 0.29 \\
\hline ITL & $0.079 * * *$ & 0.03 & $0.242^{* * *}$ & 0.07 & $0.570^{* * *}$ & 0.16 \\
\hline JKG & $0.065^{*}$ & 0.01 & $0.167 *$ & 0.04 & $0.422 *$ & 0.09 \\
\hline JPO & 0.014 & -0.01 & 0.088 & 0.00 & $0.701 * * *$ & 0.25 \\
\hline KOR & $0.026 *$ & 0.01 & $0.090^{*}$ & 0.02 & $0.297^{* *}$ & 0.34 \\
\hline KIN & 0.012 & -0.02 & 0.030 & -0.02 & 0.043 & 0.07 \\
\hline MLY & $0.077^{* *}$ & 0.03 & $0.288 * * *$ & 0.10 & $0.940^{* * *}$ & -0.02 \\
\hline MEI & $0.298^{* * *}$ & 0.14 & $0.713^{* * *}$ & 0.25 & $1.323 * * *$ & 0.34 \\
\hline MEX & $0.077 * * *$ & 0.02 & $0.184 * *$ & 0.03 & $0.416^{*}$ & 0.33 \\
\hline NGR & $0.168^{* * *}$ & 0.11 & $0.497 * * *$ & 0.28 & $0.737^{* * *}$ & 0.05 \\
\hline PTG & $0.081 * *$ & 0.03 & $0.231 * *$ & 0.07 & $0.595 * * *$ & 0.43 \\
\hline $\mathrm{ROC}$ & $0.057^{*}$ & 0.01 & 0.136 & 0.02 & $0.530^{* *}$ & 0.20 \\
\hline SNG & $0.139 * * *$ & 0.07 & $0.366 * * *$ & 0.16 & $0.778^{* * *}$ & 0.10 \\
\hline SPN & 0.022 & 0.00 & 0.079 & 0.02 & $0.400^{* *}$ & 0.35 \\
\hline TAW & 0.006 & -0.00 & 0.027 & -0.00 & 0.179 & 0.12 \\
\hline THA & $0.061 * * *$ & 0.02 & $0.149 * *$ & 0.14 & 0.305 & 0.03 \\
\hline THC & $0.192 * * *$ & 0.06 & $0.615 * * *$ & 0.04 & $1.727^{* * *}$ & 0.05 \\
\hline TRK & 0.029 & 0.00 & 0.036 & -0.00 & 0.025 & 0.36 \\
\hline UKF & $0.247^{* * *}$ & 0.10 & $0.512 * * *$ & 0.15 & $1.091^{* * *}$ & -0.01 \\
\hline AVG & 0.135 & 0.05 & 0.336 & 0.11 & 0.667 & 0.18 \\
\hline
\end{tabular}


B. Cumulative Return on the Net Asset Value Is Regressed on the Discount

\begin{tabular}{|c|c|c|c|c|c|c|}
\hline \multirow[b]{2}{*}{ Fund } & \multicolumn{2}{|c|}{$\begin{array}{c}\text { Return Horizon }= \\
1 \text { week }\end{array}$} & \multicolumn{2}{|c|}{$\begin{array}{c}\text { Return Horizon }= \\
4 \text { weeks }\end{array}$} & \multicolumn{2}{|c|}{$\begin{array}{c}\text { Return Horizon }= \\
13 \text { weeks }\end{array}$} \\
\hline & $\beta_{i}^{a}$ & Adjusted $R^{2}$ & $\beta_{i}^{a}$ & Adjusted $R^{2}$ & $\beta_{i}^{a}$ & Adjusted $R^{2}$ \\
\hline AUS & $-0.060 * * *$ & 0.06 & $-0.204 * * *$ & 0.18 & $-0.444 * * *$ & 0.30 \\
\hline BRZ & -0.026 & 0.00 & -0.086 & 0.01 & -0.137 & 0.01 \\
\hline BRE & -0.002 & -0.02 & 0.222 & 0.01 & 0.109 & -0.03 \\
\hline CHL & 0.016 & -0.00 & 0.054 & 0.00 & $0.409^{* *}$ & 0.10 \\
\hline EGR & -0.078 & 0.01 & -0.036 & -0.01 & -0.128 & 0.00 \\
\hline EMX & 0.030 & -0.00 & 0.080 & -0.00 & 0.680 & 0.05 \\
\hline FAS & -0.037 & 0.01 & -0.072 & 0.00 & -0.147 & 0.01 \\
\hline FIB & 0.005 & -0.00 & 0.009 & -0.00 & -0.047 & 0.00 \\
\hline FPH & -0.001 & -0.01 & -0.006 & -0.01 & 0.080 & 0.01 \\
\hline FRG & 0.039 & -0.00 & $0.222^{*}$ & 0.05 & $0.248^{* *}$ & 0.02 \\
\hline FTG & -0.027 & -0.00 & -0.007 & -0.01 & -0.025 & -0.01 \\
\hline GER & -0.022 & 0.01 & -0.052 & 0.01 & -0.071 & 0.01 \\
\hline GSP & 0.020 & -0.01 & 0.074 & -0.00 & 0.183 & 0.00 \\
\hline SWH & -0.016 & -0.00 & -0.031 & -0.00 & -0.054 & -0.00 \\
\hline ING & - & - & - & - & - & - \\
\hline IND & $-0.046^{* *}$ & 0.04 & $-0.202^{* * *}$ & 0.14 & $-0.727 * * *$ & 0.37 \\
\hline IRE & -0.006 & -0.01 & 0.026 & -0.01 & 0.214 & 0.02 \\
\hline ITL & -0.017 & 0.00 & -0.043 & 0.01 & $-0.137^{*}$ & 0.03 \\
\hline JKG & -0.031 & 0.02 & $-0.109 * * *$ & 0.08 & $-0.234^{*}$ & 0.08 \\
\hline JPO & $-0.054^{*}$ & 0.03 & $-0.171^{* *}$ & 0.08 & -0.189 & 0.03 \\
\hline KOR & -0.009 & 0.00 & -0.020 & 0.00 & -0.054 & 0.01 \\
\hline KIN & -0.063 & 0.02 & $-0.293^{* *}$ & 0.19 & $-1.090 * * *$ & 0.82 \\
\hline MLY & 0.001 & -0.00 & $0.082 *$ & 0.03 & $0.363^{* *}$ & 0.21 \\
\hline MEI & $0.054^{*}$ & 0.02 & $0.162^{*}$ & 0.04 & 0.507 & 0.09 \\
\hline MEX & -0.016 & -0.00 & -0.063 & 0.00 & -0.094 & -0.00 \\
\hline NGR & -0.028 & 0.00 & -0.059 & 0.01 & -0.054 & -0.00 \\
\hline PTG & -0.013 & -0.00 & -0.057 & 0.02 & -0.159 & 0.04 \\
\hline ROC & $-0.053^{* *}$ & 0.02 & $-0.178^{* *}$ & 0.05 & -0.437 & 0.09 \\
\hline SNG & 0.002 & -0.01 & 0.037 & -0.00 & 0.104 & 0.00 \\
\hline SPN & -0.004 & -0.00 & -0.013 & -0.00 & -0.020 & -0.00 \\
\hline TAW & $-0.044 * * *$ & 0.06 & $-0.171^{* * *}$ & 0.18 & $-0.440 * * *$ & 0.35 \\
\hline THA & -0.016 & 0.00 & -0.035 & 0.00 & 0.602 & 0.08 \\
\hline THC & -0.050 & 0.00 & -0.004 & -0.01 & -0.147 & 0.02 \\
\hline TRK & -0.034 & 0.00 & -0.111 & 0.02 & -0.386 & 0.09 \\
\hline UKF & 0.003 & -0.00 & 0.003 & -0.00 & 0.387 & 0.07 \\
\hline AVG & -0.017 & 0.01 & -0.031 & 0.03 & -0.039 & 0.08 \\
\hline
\end{tabular}

${ }^{2}$ Results from the following regressions are presented:

Panel A:

$$
\sum_{n=1}^{N} R F N D_{i, t+n}=\alpha_{i}^{f}+\beta_{i}^{f} D I S C_{i, t}+e_{i, t}
$$

(continued) 
Table 8.6

(continued)

Panel B:

$$
\sum_{n=1}^{N} R N A V_{i, t+n}=\alpha_{i}^{f}+\beta_{i}^{f} D I S C_{i, t}+e_{i, t}
$$

where $R F N D_{i}$ and $R N A V_{i}$ are the returns on fund ${ }_{i}$ and on the net assets of fund , respectively, $D I S C_{i, r}$ is the discount on the $i^{\text {th }}$ country fund at the end of week $t . \alpha_{i}$ and $\beta_{i}$ are fund-specific parameters. The regressions are generated for cumulative return horizons of one, four, and thirteen weeks $(N=1,4,13)$. Test statistics are based on standard errors corrected for conditional heteroscedasticity $(N=1)$ and for autocorrelation of order $N-1(N=4,13)$ using the methods in White 1980 and Newey and West 1987, respectively.

*indicates significance at the 10 percent level. **indicates significance at the 5 percent level. $* * *$ indicates significance at the 1 percent level.

gests that persistent discounts across country funds imply that fund discounts may be subject to a common (systematic) source of risk. If U.S. investors act on general bullish and bearish sentiment which affects all country funds, their behavior is likely to affect country fund prices systematically, resulting in a common component across the fund discounts. ${ }^{19}$

To capture a possible common component across the fund discounts, we estimate a parametric version of the "single index" models discussed by Sargent and Sims (1977). Estimation of the unobserved component model provides a succinct test of the presence of a common component across funds as well as a convenient tool for analysis. The empirical model is as follows. Each discount $D I S C_{i, t}$ is hypothesized to move contemporaneously with an unobserved scalar ("index"), $Z_{p}$, which is common to all funds, and an idiosyncratic component $\varepsilon_{i, r^{\prime}}$ Both the unobserved index and the idiosyncratic component of each fund's discount are modeled as having linear stochastic structures. In addition, $Z_{t}$ is assumed only to enter each fund's discount contemporaneously. The formulation is

$$
\begin{gathered}
D I S C_{i, t}=B Z_{t}+\mathrm{u}_{i, t} ; \\
\alpha(L) Z_{t}=e_{i} ; \delta_{t}(L) u_{i, t}=v_{i, t} i=1, \ldots, K,
\end{gathered}
$$

where $\alpha(L)$ and $\delta(L)$ are polynomials in the lag operator $L, e_{t}$ and $\nu_{t}$ are white noise errors, and $K$ represents the number of assets. The main identifying assumption of the model expresses the notion that comovements in the multiple discounts arise from a single source $Z_{r}$. This is formalized by assuming that the terms $u_{i, t}, i=1, \ldots, K$, and the term $Z$ are mutually uncorrelated at all leads and lags.

Because estimation of the model requires exactly overlapping time-series of

19. Lee, Shleifer, and Thaler (1991) examine the comovements in discounts by computing the pairwise correlations across ten funds using monthly data over a period of twenty years. They conclude that correlations are high enough to suggest that the discounts of different domestic funds move together. 
fund discounts, we choose the estimation period in order to balance the need for a long weekly time series and the need to include many and diverse funds. We restricted the sample to include the nine oldest funds (MEX, FAS, GER, SWH, ITL, KOR, MLY, TAW, and UKF) over the period January 1988 to January 1993. We estimate the model by first casting it into a (vector) state-space form and then applying the Kalman filter to evaluate the likelihood function. ${ }^{20}$ To simplify estimation, we further assume that $\alpha(L)$ and $\delta(L)$ represent firstorder polynomials. In addition, we normalize the variance of the innovation in the common factor, $v_{t}$, to equal $1 .{ }^{21}$

The results from estimating the unobserved components model are given in table 8.7, panel A. Several features are worth noting. First, seven of the nine slope coefficients, $B_{i}$, that relate the common factor to the discount of each country fund, are significant, while two are marginally significant. Furthermore, the estimate of the autoregressive coefficient of the common component, $\alpha$, is 0.96 (standard error $=0.03$ ). This implies a level of persistence of the common component (half-life $=$ seventeen weeks) considerably greater than the persistence of the idiosyncratic components implied by the estimates of the $\delta$, whose median value is 0.78 (half-life $=$ three weeks). A likelihood ratio test of the hypothesis that there is no common factor, that is, that the $B_{i}$ and $\alpha$ are all jointly zero, strongly rejects: $\chi^{2}(10)=131.4 ; p$-value $=0.00$. Based on the estimates of the slope coefficients $\left(B_{i}\right)$, the estimates of the autoregressive parameters $\left(\alpha\right.$ and $\left.\delta_{i}\right)$, and the estimates of the variances of the idiosyncratic errors, we computed for each of the nine funds the fraction of the unconditional variance of the discount attributable to the common factor. We found that on average, the variance in the common factor accounts for roughly 20 percent of the variance in the discounts (last column, panel A).

Inspection of the errors generated by the model estimated above reveals serial correlation in the residuals. In other words, specifying AR(1) processes for the common and idiosyncratic components is not general enough to fully capture the dynamic behavior of discounts. Checking the robustness of our results to a higher-order dynamic specification could be done, in principle, by allowing more lags in the factor dynamics. However, this turns out to be computationally costly. Instead, we applied the Kalman filter to prewhitened dis-

20. The Kalman filter is a well-known way to compute the Gaussian likelihood function. The filter recursively constructs minimum mean-square-error estimates of the unobserved state vector, given observations of the measurable variables. This has two parts: the transition equation and the measurement equations. The transition equation describes the evolution of the unobserved state variables, $Z$, and $u_{i, i}$, and their respective lags. The measurement equation relates the observed variables to the state variable.

21. A specification test for the model was also conducted (Sargent and Sims 1977). Specifically, we test the restriction that all comovements in the series arise from a single source against the alternative that they have an unrestricted covariance matrix. The test examines the implication that the spectral density matrix of the vector $D I S C_{\text {, }}$, constructed by arranging the fund discounts into a $K x l$ vector, has a factor structure. We perform the test by partitioning the cross-spectrum into five equally spaced frequency bands. The $\chi^{2}$ statistic has 275 degrees of freedom and equals 130.65 with a $p$-value of 0.99 . This provides little evidence against the restrictions. 
A. The estimate of $\alpha$, the autoregressive parameter for the common factor $Z_{r}$, was estimated to be 0.96 (standard error 0.031 ). The parameters pertaining to the individual funds were estimated as follows:

\begin{tabular}{llcc}
\hline & \multicolumn{2}{c}{ Parameter } & $\begin{array}{c}\text { Contribution of } \\
\text { Fund }\end{array}$ \\
\cline { 2 - 3 } & \multicolumn{1}{c}{$B_{i}$} & $\delta_{i}$ & $\begin{array}{c}\text { Vance of } Z \text { to Variance } \\
\text { of } D I S C_{i}\end{array}$ \\
\hline FAS & $0.0082^{* *}$ & 0.67 & 0.186 \\
GER & $0.0161^{* *}$ & 0.74 & 0.411 \\
SWH & $0.0081^{* *}$ & 0.57 & 0.286 \\
ITL & $0.0098^{* *}$ & 0.78 & 0.218 \\
KOR & $0.0059^{*}$ & 0.98 & 0.077 \\
MLY & $0.0120^{* *}$ & 0.85 & 0.263 \\
MEX & $0.0080^{* *}$ & 0.81 & 0.120 \\
TAW & $0.0069^{*}$ & 0.95 & 0.056 \\
UKF & $0.0048^{* *}$ & 0.64 & 0.136 \\
\cline { 2 - 4 } AVG & 0.0088 & 0.78 & 0.195 \\
\hline
\end{tabular}

B.

\begin{tabular}{llcc}
\hline Fund & \multicolumn{2}{c}{ Parameter } & $\begin{array}{c}\text { Contribution of } \\
\text { Variance of } Z \text { to Variance } \\
\text { of } A_{i}(L) D I S C_{i}\end{array}$ \\
\cline { 2 - 4 } FAS & \multicolumn{1}{c}{$B_{i}$} & $\sigma\left(v_{i}\right)$ & 0.155 \\
GER & $0.027^{* * *}$ & 0.056 & 0.298 \\
SWH & $0.047^{* * *}$ & 0.072 & 0.274 \\
ITL & $0.028^{* * *}$ & 0.045 & 0.129 \\
KOR & $0.024^{* * *}$ & 0.063 & 0.061 \\
MLY & $0.019^{* *}$ & 0.075 & 0.185 \\
MEX & $0.033^{* * *}$ & 0.070 & 0.101 \\
TAW & $0.025^{* * *}$ & 0.076 & 0.061 \\
UKF & $0.026^{* *}$ & 0.102 & 0.272 \\
AVG & $0.024^{* * *}$ & 0.039 & 0.171 \\
\hline
\end{tabular}

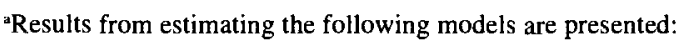

Panel A:

$$
\operatorname{DISC}_{i, t}=B_{i} Z_{t}+u_{i, t} ; Z_{t}=\alpha Z_{t-1}+e_{t} ; u_{i, t}=\delta_{i} u_{i, t-1}+v_{i, t} ; i=1, \ldots, K
$$

Panel B:

$$
A_{i}(L) D I S C_{i, t}=B_{i} Z_{1}+u_{i, r} ; Z_{i}=e_{1} ; u_{i, t}=v_{i, t} ; i=1, \ldots, K
$$

where $e_{t}$ and $v_{i, t}$ are normally distributed white noise errors, $Z$ represents the common component in discount variation, $u_{i, t}$ is the idiosyncratic component of the discount of country fund, $i, L$ is the lag operator, and $\alpha$ and $\delta_{i}$ are autoregressive parameters to be estimated. Each of the two models is estimated with nine country funds $(K=9)$ using weekly discount data over the period January 1988 through January 1993. The models are estimated by casting them in a vector state-space form and applying the Kalman filter to evaluate the likelihood functions. In the second model 
Table 8.7

(continued)

(panel B), the discounts for the funds are each filtered through $\left(A_{i}(L)\right.$, a polynomial in $L$, to "prewhiten" the data. The choice of $A_{i}$ for $i=1, \ldots, K$, is described in the text. In each case, the variance of $e_{i}$ is normalized to 1 , while $\sigma\left(v_{i}\right)$, the standard error of $v_{i}$, is an estimable parameter.

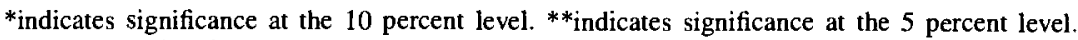
$* * *$ indicates significance at the 1 percent level.

counts for the nine country funds under consideration and tested for a common component in the innovation in the country fund discounts. Formally, we replaced $D I S C_{i, t}$ in the formulation above, with $\mathrm{A}_{i}(L) D I S C_{i, t}$ (for $i=1, \ldots, K$ ) and forced the $Z_{t}$ and $u_{i, t}$ to be white noise. $A_{i}(L)$ is a polynomial in the lag operator which "whitens" the discounts. ${ }^{22}$

Results from estimating the model using the prewhitened data are in panel B of table 8.7. The estimates of the $B_{i}$, the exposure of the fund discounts to the common innovation, are now highly significant for all nine funds. The likelihood ratio test of the hypothesis that there is no common disturbance strongly rejects $\left(\chi^{2}(9)=140.6 ; p\right.$-value $\left.=0.00\right)$, and simple diagnostic tests on the errors generated by the model reveal no evidence of serial correlation. The average estimate of the contribution of the common factor to the variances of the country fund discounts remains roughly 17 percent. Overall, the results presented in table 8.7 provide strong evidence of common variation across the fund discounts.

Further insight into the results can be gained by examining the behavior of the unobservable common factor during the sample period. A plot of $Z_{i}$, generated from the first model, is presented in figure 8.3. Because the variance of the innovation in $Z_{t}$ is normalized to 1 , the reader should focus on relative changes instead of the level. The most noticeable feature of the common factor is its behavior in late 1989, which coincides with the fall of the Berlin Wall. ${ }^{23}$ Although the noise-trader model does not explicitly specify any one source of investor misperception or sentiment, Shiller (1984) discusses one characterization of sentiment as a change in investors' attitude toward future returns, which may occur as an arbitrary social reaction to some widely noted events. In the introduction, we noted that the fall of the Berlin Wall might qualify as such an event. The analysis of this subsection seems to confirm that the event was associated with an innovation in the unobserved common component in the discount across the country funds. Compared with the sentiment model, initial public offerings of country funds shown in figure 8.1 peaked in $1990 .{ }^{24}$

22. To prewhiten the discount data, autoregressions of orders one through twelve were run. The order of the process was selected so that it minimized the maximum deviation from the cumulative spectrum of a white noise process.

23. Excluding the Germany Fund from the above procedures does not lead to a significant change in the test results or in the series plotted in figure 8.3.

24. During the 1980s, offerings of domestic-equity funds peaked in 1986 and 1987, prior to the stock market crash. 


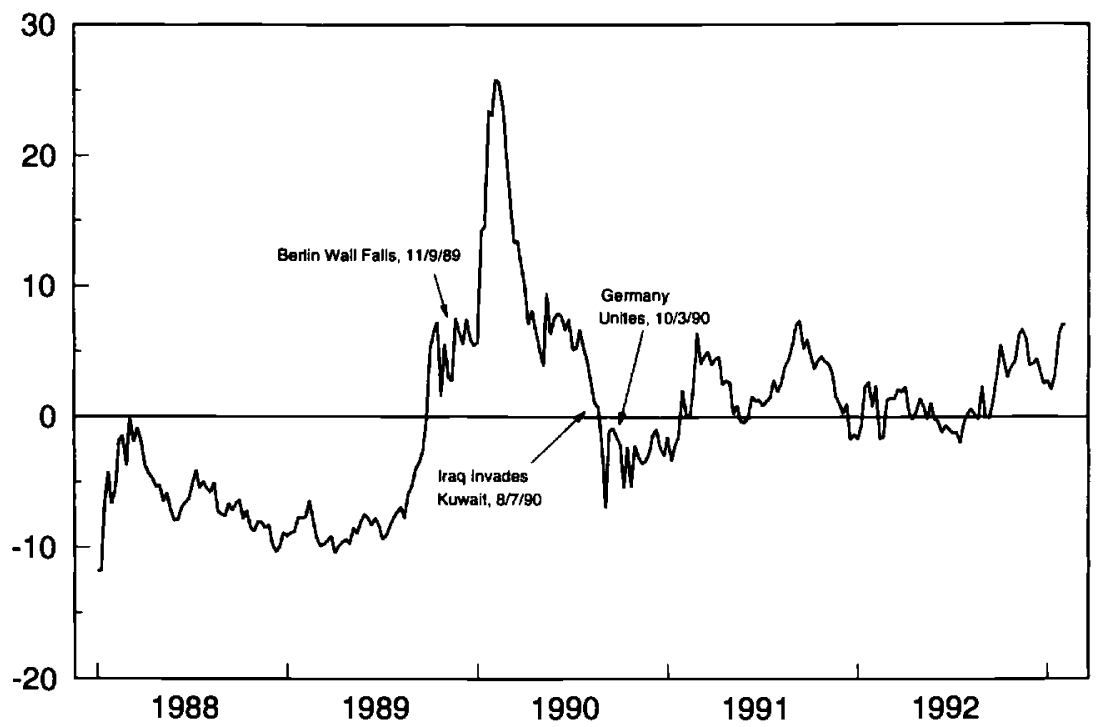

Fig. 8.3 Common component in country fund premia/discounts

\subsection{Sources of Variation in Country Fund Discounts}

Although widely noted events may account for some large coherent swings in sentiment, casual observation suggests that they cannot account for all of the variation in the discounts of country funds. In this section we examine the response of fund prices to specific aggregate financial variables such as the exchange rate, the index of the host country's stock prices, an index of world stock prices, and indices of stock prices for large- and small-capitalization U.S. firms. Our aim is to explore potential sources of the variation in fund discounts that we documented in earlier sections, and to examine whether or not the noise-trader model can accommodate some of the evidence we uncover. In order to shed some light on the ability of models with rational agents and investment restrictions to explain the time-variation in discounts, we also perform the empirical analysis separately for funds whose host countries restrict international investment from funds whose host countries allow free capital movements. We also examine the differences between host countries with developed stock markets and those with emerging stock markets and between Asian, European, and Latin American funds.

\subsubsection{Specification}

For each country fund $i$ we estimate basic regression equations of the form

$$
\sum_{n=1}^{N} R E T_{i, t+n}=\beta_{0}+\beta_{1} D I S C_{i, t}+\sum_{j=2}^{J} \beta_{j}\left(\sum_{n=1}^{N} \mathrm{X}_{j, t+n}\right)+\mathrm{e}_{i, t+n},
$$


where $R E T$ denotes alternatively the weekly return on the country fund, $R F N D$, the weekly return on the NAV, RNAV, and the excess return on the country fund, $R F N D-R N A V$. DISC is the country fund discount, and is observed at the beginning of the holding period prior to the realization of the cumulative return $\Sigma R E T$. Hence, the equation is an extension of the earlier forecasting equations of section 8.4. The $X_{i} \mathrm{~s}$ are weekly returns of different financial variables observed simultaneously with the dependent variable. $N$ denotes the holding period horizon in weeks. As before, we show results for $N=$ one, four, and thirteen weeks.

When the dependent variable is $R F N D-R N A V$, the above equation becomes the empirical counterpart of equation (14) of the sentiment model. In this framework, DISC captures the level of sentiment in the beginning of the holding period, while the remaining independent variables capture the influence of innovations in sentiment during the holding period. Being financial rates of return, the $X_{j}$ variables are nearly serially uncorrelated and thus may readily capture innovations in sentiment.

The first financial variable that we use as an explanatory variable in the regression is fund-specific and represents the cumulative return on a broad index of stocks from fund $i$ 's host country, RFST. RFST is included to capture the component of returns that are attributed to local currency variation in the host country's stock market. The second variable, $R E X$, is the weekly dollar return on holding the foreign country's currency. Changes in the value of the dollar relative to the foreign currency result in an unambiguous change in the dollar value of the fundamental. While small exchange rate movements that are perceived by the market as temporary may not affect the fund price and thus may move the discount/premium, large changes in the dollar value of foreign currency ought to move the price of the fund sufficiently in order to leave the discount/premium unaffected. Nonetheless, casual observation of the events of September 1992 suggest otherwise. This month saw an appreciation of the dollar as speculators bet against certain weak European currencies in anticipation of the withdrawals from the $E R M$, which did occur. The resultant appreciation of the dollar was associated with significant drops in the premia of the European country funds: as the NAV (translated to dollars) fell, the price of the funds generally did not.

Our earlier empirical analysis showed that country fund discounts shared a common component. We now include three explanatory variables that are common to all country funds in order to capture some of this common variation. The first of these variables, $R W R D$, is the dollar return on a world stock market index. The next variable, $R S P$, is the dollar return on an index of large U.S. stocks. The last variable $R S M L-R S P$, represents the excess return on an index of small-capitalization U.S. stocks over the return on the large stocks. Under Lee, Shleifer, and Thaler's (1991) assertion that noise trader sentiment is associated with individual investors, and thus largely affects small-cap stocks, an index of large U.S. stocks is more apt to capture variation in U.S. 
fundamentals, while the excess return on small caps will capture variation in noise trader sentiment. Detailed definitions of all variables are given in table 8.3.

\subsubsection{Results}

Table 8.8A presents the main results. In order to abstract from unnecessary details, the table presents only summary results for all funds from stacked regressions. The stacked regressions restrict the slope coefficients to be the same across funds but allow individual fund intercepts. In addition to the multivariate regression described above, table $8.8 \mathrm{~A}$ also provides results from univariate regressions in which the cumulative returns $\Sigma R F N D, \sum R N A V$, and $\Sigma R F N D$ - $\Sigma R N A V$ are separately regressed on each of the independent variables. Panel $\mathrm{A}$ of table $8.8 \mathrm{~A}$ reports the results for the one-week holding-period horizon, panel B the four-week horizon, and panel $\mathrm{C}$ the thirteen-week horizon. ${ }^{25}$

The fund discount has strong explanatory power for fund returns $(\Sigma R F N D)$ in both the multivariate and univariate regressions. As already noted in the earlier sections, high discounts are associated with positive future returns on the fund but negative future returns on the net assets. As a result, the association with excess fund returns, $\Sigma R F N D-\Sigma R N A V$, is even stronger. Observe also that as the holding period horizon increases, the absolute size of the $\beta_{1}$ coefficients also increases. There is strong reversion of the fund price toward the NAV, as well as a smaller but statistically significant reversion of the NAV toward the fund price. A relative fall of the fund price-that is, an increase in the discount-by 100 basis points is followed by an increase in the fund price and a decrease in the NAV. The multivariate regression shows that after thirteen weeks the fund price has increased by 37.5 basis points and the NAV has fallen by 6.4 basis points, thus 44 of the original 100-basis-points gap have been eliminated.

Turning to the response of country fund prices to local stock returns, ¿RFST, country fund returns themselves have significantly lower betas than do the NAV returns. The average local market beta for the NAV return (fund return) is $0.608(0.428)$ for the one-week return horizon and $0.718(0.600)$ for the thirteen-week horizon. ${ }^{26}$ These observed differences between the fund and

25. The Newey-West $t$-statistics of panels B and C treat the stacked data as a single time-series, that is, they do not recognize the break in the stacked data between two separate funds. This fact is likely to bias the reported $t$-statistics slightly downward.

26. It is interesting to note that the beta of the underlying assets (NAV) with the local market is significantly less than one in the multivariate regressions that control for exchange-rate changes. This potentially reflects one of two things. First, the foreign equity holdings of the funds may indeed be less "risky" than the foreign market. By holding a disproportionate amount of small firms, the fund reduces its exposure to a foreign market index that may be dominated by two or three large firms (Mexico is well-known example). Second, a country fund is never 100 percent fully invested in the foreign-equity market it represents, especially if the fund is new and still holds a large portion of the IPO proceeds as cash. In general, the fund's NAV may represent nonequity assets such as local and dollar-denominated time deposits and repurchase agreements, tax refunds, interest receivable, and currency options. 
A. Cumulative Return Horizon Is One Week $(N=1)$

\begin{tabular}{|c|c|c|c|c|c|c|c|c|}
\hline \multirow{2}{*}{$\begin{array}{l}\text { Dependent } \\
\text { Variable }\end{array}$} & \multicolumn{6}{|c|}{ Multivariate Regression-Slope Coefficients and $t$-statistics } & \multirow[b]{2}{*}{ Adjusted $R^{2}$} & \multirow{2}{*}{$\begin{array}{l}\text { Number of } \\
\text { Observations }\end{array}$} \\
\hline & $D I S C$ & $\sum R F S T$ & $\sum R E X$ & $\sum R W R D$ & $\sum R S P$ & $\sum R S M L-\Sigma R S P$ & & \\
\hline ¿RFND & $\begin{array}{c}0.059 \\
(10.1)\end{array}$ & $\begin{array}{c}0.428 \\
(21.3)\end{array}$ & $\begin{array}{c}0.088 \\
(1.96)\end{array}$ & $\begin{array}{c}0.500 \\
(10.5)\end{array}$ & $\begin{array}{r}0.377 \\
(7.26)\end{array}$ & $\begin{array}{r}0.285 \\
(5.48)\end{array}$ & 0.26 & 6469 \\
\hline ¿RNAV & $\begin{array}{r}-0.009 \\
(-2.89)\end{array}$ & $\begin{array}{l}0.608 \\
(24.9)\end{array}$ & $\begin{array}{l}0.621 \\
(13.0)\end{array}$ & $\begin{array}{r}0.153 \\
(6.42)\end{array}$ & $\begin{array}{r}-0.017 \\
(-0.75)\end{array}$ & $\begin{array}{r}0.070 \\
(2.51)\end{array}$ & 0.63 & 6469 \\
\hline$\sum$ RFND- $\Sigma$ RNAV & $\begin{array}{c}0.069 \\
(10.6)\end{array}$ & $\begin{array}{l}-0.180 \\
(-6.44)\end{array}$ & $\begin{array}{c}-0.533 \\
(-8.53)\end{array}$ & $\begin{array}{r}0.344 \\
(6.99)\end{array}$ & $\begin{array}{r}0.394 \\
(7.22)\end{array}$ & $\begin{array}{r}0.215 \\
(3.79)\end{array}$ & 0.11 & 6469 \\
\hline
\end{tabular}

Univariate Regressions-Slope Coefficients, $t$-statistics, and Adjusted $R^{2}$

\begin{tabular}{|c|c|c|c|c|c|c|}
\hline & \\
\hline $\begin{array}{l}\text { Dependent } \\
\text { Variable }\end{array}$ & $D I S C$ & $\sum R F S T$ & $\sum R E X$ & $\sum R W R D$ & $\sum R S P$ & $\sum R S M L$ \\
\hline \multirow[t]{3}{*}{$\Sigma$ RFND } & 0.053 & 0.537 & 0.019 & 1.092 & 0.969 & 0.941 \\
\hline & $(8.93)$ & $(24.5)$ & $(0.35)$ & $(24.6)$ & $(20.2)$ & (23.1) \\
\hline & {$[0.02]$} & [0.16] & {$[0.00]$} & [0.14] & {$[0.11]$} & [0.13] \\
\hline \multirow[t]{3}{*}{$\Sigma \mathrm{RNAV}$} & -0.021 & 0.611 & 0.491 & 0.608 & 0.380 & 0.429 \\
\hline & $(-5.35)$ & $(23.5)$ & $(11.0)$ & $(21.3)$ & $(12.1)$ & (13.4) \\
\hline & {$[0.01]$} & {$[0.54]$} & [0.05] & {$[0.11]$} & {$[0.04]$} & {$[0.07]$} \\
\hline \multirow[t]{3}{*}{$\Sigma$ RFND $-\Sigma$ RNAV } & 0.074 & -0.074 & -0.472 & 0.484 & 0.590 & 0.511 \\
\hline & $(12.23)$ & $(-2.57)$ & $(-8.66)$ & (11.3) & (13.1) & $(12.4)$ \\
\hline & {$[0.04]$} & {$[0.00]$} & {$[0.02]$} & {$[0.03]$} & {$[0.04]$} & {$[0.04]$} \\
\hline
\end{tabular}


B. Cumulative Return Horizon Is Four Weeks $(N=4)$

\begin{tabular}{|c|c|c|c|c|c|c|c|c|}
\hline \multirow{2}{*}{$\begin{array}{l}\text { Dependent } \\
\text { Variable }\end{array}$} & \multicolumn{6}{|c|}{ Multivariate Regression-Slope Coefficients and $t$-statistics } & \multirow[b]{2}{*}{ Adjusted $R^{2}$} & \multirow{2}{*}{$\begin{array}{c}\text { Number of } \\
\text { Observations }\end{array}$} \\
\hline & $D I S C$ & $\Sigma R F S T$ & $\sum R E X$ & $\sum R W R D$ & $\sum R S P$ & $\Sigma R S M L-\Sigma R S P$ & & \\
\hline$\sum$ RFND & $\begin{array}{l}0.155 \\
(10.9)\end{array}$ & $\begin{array}{l}0.557 \\
(23.9)\end{array}$ & $\begin{array}{l}0.470 \\
(10.5)\end{array}$ & $\begin{array}{l}0.584 \\
(11.7)\end{array}$ & $\begin{array}{r}0.118 \\
(2.19)\end{array}$ & $\begin{array}{r}0.347 \\
(8.01)\end{array}$ & 0.46 & 6367 \\
\hline$\sum$ RNAV & $\begin{array}{c}-0.028 \\
(-3.46)\end{array}$ & $\begin{array}{c}0.697 \\
(50.0)\end{array}$ & $\begin{array}{l}0.700 \\
(18.8)\end{array}$ & $\begin{array}{r}0.111 \\
(4.49)\end{array}$ & $\begin{array}{r}0.020 \\
(0.85)\end{array}$ & $\begin{array}{r}0.031 \\
(1.36)\end{array}$ & 0.77 & 6367 \\
\hline$\sum \mathrm{RFND}-\Sigma \mathrm{RNAV}$ & $\begin{array}{l}0.183 \\
(11.8)\end{array}$ & $\begin{array}{r}-0.140 \\
(-5.68)\end{array}$ & $\begin{array}{r}-0.230 \\
(-4.13)\end{array}$ & $\begin{array}{c}0.473 \\
(9.12)\end{array}$ & $\begin{array}{r}0.097 \\
(1.76)\end{array}$ & $\begin{array}{c}0.316 \\
(6.99)\end{array}$ & 0.19 & 6367 \\
\hline
\end{tabular}

Univariate Regressions-Slope Coefficients, $t$-statistics, and Adjusted $R^{2}$

\begin{tabular}{|c|c|c|c|c|c|c|}
\hline $\begin{array}{l}\text { Dependent } \\
\text { Variable }\end{array}$ & $D I S C$ & $\sum R F S T$ & $\sum R E X$ & $\sum R W R D$ & $\sum R S P$ & $\sum R S M L$ \\
\hline \multirow[t]{3}{*}{$\sum$ RFND } & 0.143 & 0.649 & 0.164 & 1.331 & 1.244 & 0.913 \\
\hline & $(8.03)$ & $(24.2)$ & $(2.38)$ & $(21.6)$ & $(18.2)$ & $(19.7)$ \\
\hline & {$[0.04]$} & {$[0.31]$} & {$[0.00]$} & {$[0.24]$} & {$[0.20]$} & {$[0.21]$} \\
\hline \multirow[t]{3}{*}{$\Sigma$ RNAV } & -0.064 & 0.675 & 0.419 & 0.745 & 0.656 & 0.488 \\
\hline & $(-4.42)$ & $(37.2)$ & $(5.40)$ & $(14.0)$ & $(11.0)$ & $(11.4)$ \\
\hline & {$[0.01]$} & {$[0.66]$} & {$[0.03]$} & {$[0.14]$} & {$[0.11]$} & {$[0.12]$} \\
\hline \multirow[t]{3}{*}{$\Sigma$ RFND $-\Sigma$ RNAV } & 0.208 & -0.027 & -0.255 & 0.586 & 0.588 & 0.425 \\
\hline & $(13.8)$ & $(-1.04)$ & $(-4.73)$ & $(13.4)$ & $(13.1)$ & $(13.3)$ \\
\hline & {$[0.12]$} & {$[0.00]$} & {$[0.01]$} & {$[0.07]$} & {$[0.07]$} & {$[0.07]$} \\
\hline
\end{tabular}


C. Cumulative Return Horizon Is Thirteen Weeks $(N=13)$

\begin{tabular}{|c|c|c|c|c|c|c|c|c|}
\hline \multirow{2}{*}{$\begin{array}{l}\text { Dependent } \\
\text { Variable }\end{array}$} & \multicolumn{6}{|c|}{ Multivariate Regression-Slope Coefficients and $t$-statistics } & \multirow[b]{2}{*}{ Adjusted $R^{2}$} & \multirow{2}{*}{$\begin{array}{l}\text { Number of } \\
\text { Observations }\end{array}$} \\
\hline & DISC & $\Sigma R F S T$ & $\Sigma R E X$ & $\sum R W R D$ & $\Sigma R S P$ & $\Sigma R S M L-\Sigma R S P$ & & \\
\hline$\sum$ RFND & $\begin{array}{c}0.375 \\
(11.2)\end{array}$ & $\begin{array}{c}0.600 \\
(15.8)\end{array}$ & $\begin{array}{r}0.645 \\
(9.16)\end{array}$ & $\begin{array}{r}0.487 \\
(5.34)\end{array}$ & $\begin{array}{r}0.193 \\
(2.14)\end{array}$ & $\begin{array}{r}0.187 \\
(3.05)\end{array}$ & 0.59 & 6061 \\
\hline$\Sigma \mathrm{RNAV}$ & $\begin{array}{l}-0.064 \\
(-3.28)\end{array}$ & $\begin{array}{l}0.718 \\
(29.1)\end{array}$ & $\begin{array}{l}0.751 \\
(20.9)\end{array}$ & $\begin{array}{r}0.050 \\
(1.26)\end{array}$ & $\begin{array}{r}0.089 \\
(1.94)\end{array}$ & $\begin{array}{l}-0.010 \\
(-0.30)\end{array}$ & 0.82 & 6061 \\
\hline$\Sigma$ RFND- $\Sigma$ RNAV & $\begin{array}{l}0.439 \\
(12.0)\end{array}$ & $\begin{array}{l}-0.120 \\
(-3.73)\end{array}$ & $\begin{array}{l}-0.106 \\
(-1.31)\end{array}$ & $\begin{array}{r}0.437 \\
(4.61)\end{array}$ & $\begin{array}{r}0.104 \\
(1.10)\end{array}$ & $\begin{array}{c}0.196 \\
(3.35)\end{array}$ & 0.36 & 6061 \\
\hline
\end{tabular}

Univariate Regressions-Slope Coeficients, $t$-statistics, and Adjusted $R^{2}$

\begin{tabular}{|c|c|c|c|c|c|c|}
\hline $\begin{array}{l}\text { Dependent } \\
\text { Variable }\end{array}$ & $D I S C$ & $\sum R F S T$ & $\sum R E X$ & $\sum R W R D$ & $\Sigma R S P$ & $\Sigma R S M L$ \\
\hline \multirow[t]{3}{*}{$\Sigma$ RFND } & 0.396 & 0.640 & 0.056 & 1.633 & 1.556 & 0.878 \\
\hline & $(7.60)$ & $(16.7)$ & $(0.55)$ & $(17.3)$ & $(17.3)$ & $(16.0)$ \\
\hline & {$[0.09]$} & {$[0.36]$} & {$[0.00]$} & {$[0.32]$} & {$[0.32]$} & {$[0.29]$} \\
\hline \multirow[t]{3}{*}{$\Sigma$ RNAV } & -0.132 & 0.644 & 0.319 & 0.828 & 0.855 & 0.482 \\
\hline & $(-3.16)$ & $(30.0)$ & $(3.48)$ & $(9.18)$ & $(8.44)$ & $(9.31)$ \\
\hline & {$[0.02]$} & {$[0.64]$} & {$[0.03]$} & {$[0.14]$} & {$[0.17]$} & {$[0.15]$} \\
\hline \multirow[t]{3}{*}{$\Sigma$ RFND $-\Sigma$ RNAV } & 0.528 & -0.004 & -0.263 & 0.805 & 0.701 & 0.397 \\
\hline & $(14.5)$ & $(-0.11)$ & $(-5.66)$ & (11.3) & $(9.85)$ & $(10.1)$ \\
\hline & {$[0.30]$} & {$[0.00]$} & {$[0.02]$} & {$[0.14]$} & {$[0.12]$} & {$[0.11]$} \\
\hline
\end{tabular}

(continued) 


\section{Table 8.8A}

(continued)

${ }^{2}$ Results from multivariate and univariate regressions are presented. The multivariate regression is of the form

$$
\begin{gathered}
\sum_{n=1}^{N} \operatorname{RET}_{i, t+n}=\beta_{1} D I S C_{i, t}+\beta_{2} \sum_{n=1}^{N} R F S T_{i, t+n}+\beta_{3} \sum_{n=1}^{N} R E X_{i, t+n}+\beta_{4} \sum_{n=1}^{N} R W R D_{t+n}+\beta_{5} \sum_{n=1}^{N} R S P_{t+n} \\
+\beta_{6} \sum_{n=1}^{N^{\prime}}\left(R S M L_{t+n}-R S P_{t+n}\right)+e_{i, t+n},
\end{gathered}
$$

where $R E T$ represents the de-meaned return on either the fund itself $\left(R F N D_{i}\right)$, the NAV of fund $i\left(R N A V_{i}\right)$, or the difference $\left(R F N D_{i}-R N A V_{i}\right)$. The regressions are estimated for cumulative return horizons of one, four, and thirteen weeks $(N=1,4,13)$ and are presented in panels $\mathrm{A}, \mathrm{B}$, and $\mathrm{C}$, respectively. The equations are estimated by stacking the country funds returns data so as to restrict the slope coefficients on the independent variables to be the same across funds. Numbers in parentheses are $t$ statistics corrected for conditional heteroscedasticity (panel A) autocorrelation of order $N-1$ (panels B and C) using the methods in White 1980 and Newey and West 1987, respectively. In the univariate regressions, the numbers in square brackets are the adjusted $R^{2}$ s. 
the NAV are significant at each horizon although the magnitude of the difference decreases with the return horizon. Country fund prices are apparently sticky with respect to movements in the host country's stock market.

A similar stickiness is observed in the response of country fund prices to the exchange rate. In the one-week horizon, fund prices show practically no reaction to changes in the exchange rate, when at the same time the NAV shows a strong response: the fund return has a beta with $R E X$ of 0.088 , while the NAV has a beta of $0.621 .{ }^{27}$ The difference between the fund beta and the NAV beta weakens at longer holding horizons. As the horizon increases, the fund price becomes statistically indistinguishable from the response of the NAV to $\Sigma R E X$.

Consistent with both the excess volatility of fund returns and the existence of a strong common component among fund discounts, table 8.8. A shows that the fund returns are excessively sensitive to all three financial returns that are common across the different country funds. In the multivariate regressions, fund returns have significantly higher betas with respect to the world stock index return $(R W R D)$ than NAV returns at every holding-period horizon. ${ }^{28}$ In the univariate regression, we find that the beta of the fund with respect to the world index is significantly larger than the beta of the NAV with the world index. The difference is not affected by the return horizon. Thus, if the world index is the appropriate benchmark for measuring wealth, the result suggests that the country funds are systematically riskier than the underlying assets.

Excess sensitivity is also present in the response to U.S. stock returns. ${ }^{29}$ For the one-week holding-period return, fund return betas with respect to $R S P$, the large-firm return index, are positive and statistically significant after controlling for the return on the foreign (host country's) market (RFST) and the world index $(R W R D)$. By comparison, the NAV return displays absolutely no exposure to $R S P$. Not surprisingly, the difference between the fund the NAV returns, $R F N D-R N A V$, has a significant positive beta with $R S P$. However, the difference between the exposures of the fund and the NAV to RSP is marginally statistically significant only at the one-week horizon $(t$-statistic $=7.22)$. At the four- and thirteen-week horizons, the difference is not significant. By contrast, and more interesting perhaps, fund return betas with respect to $R S M L-R S P$, the excess return on small U.S. firms, are significantly higher than the corresponding NAV betas at every holding period horizon, after controlling for the effects of the other financial variables.

27. The exchange rate, of course, is a component of the NAV computation (see section 8.3).

28. That the NAV retains exposure to both the world index and the U.S. index, after controlling for the local market return, may reflect the choice of fund managers to invest in firms which are export-oriented and more highly linked to the world and U.S. economies than the firms represented in the host country's stock market in general.

29. This result may be implicit in Bailey and Lim 1992. They find that country fund price volatility is higher during New York trading hours than during host-country trading hours. 


\subsubsection{Is the Noise-Trader Interpretation Reasonable?}

Table 8.8A suggests that country fund prices overreact to U.S. and world financial returns, but underreact to price innovations in the stock markets of the host countries and to currency revaluations. Can the noise-trader story accommodate these observations? Although the model does not explicitly specify the origin or source of investor sentiment and misperceptions, Shiller (1984) discusses two characterizations of sentiment which may be relevant for the pricing of country funds. In the first characterization, investors' misperceptions of returns are the result of an overreaction (or underreaction) to news about fundamentals. In this case, news about future dividends, for example, elicits an unwarranted change in the difference between noise traders' perception of future dividends on an asset and the corresponding perception of rational investors. In the context of publicly traded fund pricing, positive domestic news that increases the level of the broad U.S. market and positive "world" news that raises the level of the world market would unduly raise the fund price and decrease the discount of country funds. ${ }^{30}$ Conversely, investors may not make immediate effective use of all available information, and thus underreact to innovations in the host country's stock market and to innovations in the exchange rate.

An alternative characterization of sentiment is given by Shiller as follows: sentiment may be the result of "fluctuations in attitudes which occur widely in the population and often appear without any apparent logical reason." In this case, variations in discounts on the country funds would reflect widespread changes in noise trader sentiment unrelated to changes in fundamentals. A possible implication of this view is that the same investor sentiment that affects discounts on country funds must affect other assets as well which have little to do with the country funds. Recall from the theoretical discussion that if variation in sentiment in country funds is not correlated with fundamentals, then the same component of sentiment must appear across a wide range of assets. Although the theory does not specify which assets will be affected by the same widespread innovation in sentiment, a natural candidate for such assets is small capitalization stocks since individuals, who are more likely to trade on sentiment and to misperceive fundamental value, specialize in both smaller stocks and publicly traded funds (Lee, Shleifer, and Thaler 1991).

The results in table 8.8A suggests that both interpretations of the noisetrader model may have some validity. The strong link between changes in the discount and the financial variables $R F S T, R E X, R W R D$, and $R S P$ suggests that

30. Evidence of such a phenomenon is found in Roll (1992), which shows that international stock correlations for firms within a given industry are "too low." That country fund prices may overreact to innovations in the world index, controlling for innovations in the domestic (U.S.) index may be evidence that country fund investors have some sophistication in that they react (albeit excessively) to extranational events. Alternatively, country fund investor clienteles may include Japanese individuals who overreact to fundamental innovations in their own country, which is given much weight in the value-weighted world stock market index. 
investors overreact to fundamental revaluations that are closer to home and underreact to those with which they are less familiar, supporting the first interpretation. Moreover, the explanatory power of excess small firm returns persist even when we control for variables such as $R W R D$ and $R S P$. This provides substantial support for the second interpretation of the noise-trading hypothesis, assuming that the excess return of small firms captures a sentiment factor independent of fundamentals.

\subsubsection{Two Extensions: The Influence of the Japanese Market and the Asymmetric Effect of News}

The growth in country funds listed in New York has reflected more than just U.S. investor demand. Just as the funds may be easy sells to American individuals, they may also appeal to Japanese individuals seeking to invest abroad. On February 19, 1990, near the market peak as measured by premia paid, market observers estimated that Japanese investors owned as much as 80 percent of the Spain and Germany funds. Some sources reported that major Japanese retail brokers were the buyers as prices rose and that they then sold the shares to their clients near the market top on the (irrational) enthusiasm generated by the events in Europe. The resultant sharp drop in the country fund premia, while reflecting the invariable dissipation of ordinary-investor sentiment as modeled above, may have been accelerated by Japanese individuals selling country fund shares in New York in order to meet margin calls on their portfolios as the Japanese equity market fell in the spring of 1990. Alternatively, as part of the general "panic" on the Tokyo market between January and April 1990, Japanese individuals may have dumped international-linked assets, such as country funds, first. The fall in the prices of the funds held predominantly by the Japanese generally exceeded the fall in the Japan Nikkei index ${ }^{31}$

The events described in the financial press raise two interesting issues. First, is there any validity to the idea that prices of New York-traded funds representing Latin American, European, and Asian stocks can ostensibly diverge from fundamental value on the basis of developments in Japanese equity markets? Second, to what extent is investors' overreaction documented in table 8.8A asymmetric, in the sense that negative news about world or U.S. fundamentals has a stronger "panic" effect on country fund prices, while positive news or noise elicits a positive, albeit smaller, overreaction?

To examine the first issue, we modified the behavioral excess return equation estimated in table 8.8A to include the current and one-to-four lagged returns of the Japanese stock market. We also divided the time series of country fund returns into two subperiods: one part pertaining to the period of supposedly

31. To see how the popular press covered these events, see Tatiana Pouschine, "How Do You Say 'Manipulation' in Japanese," Forbes, 19 February 1990; Nikhil Hutheesing, "What Did In Those Country Funds," Forbes, 28 May 1990; Deborah Hargreaves, "Korea Fund Comes at Difficult Time," Financial Times, 24 April 1990; and "The Spain Fund Saga," Barron's, 25 September 1989. 
heavy Japanese involvement, that is August 1989 to July 1990, and a second part pertaining to all other weeks. The regression was estimated separately for each of the thirteen funds which spanned the period of heavy Japanese involvement. ${ }^{32}$ In general, our results were unimpressive. We found little evidence that events in the Japanese stock market had an additional effect on country fund excess returns either for the whole sample or for the period of heavy Japanese involvement. Moreover, including the current and lag values of Japanese market returns in the regression did not affect the relationship between the other financial variables (DISC, RFST, REX, RWRD, RSP, $R S M L-R S P)$ and the excess country fund returns (RFND - RNAV).

To examine asymmetries, we experimented with regressions of the form

$$
\begin{gathered}
\sum_{n=1}^{N}\left(R F N D_{i, t+n}-R N A V_{i, t+n}\right)=\beta_{0}+\beta_{1} D I S C_{i, t}+\sum_{j=2}^{J} \beta_{j}{ }^{P S}\left(\sum_{n=1}^{N} \mathrm{X}_{j, t+n}\right)^{P S} \\
+\sum_{j=2}^{J} \beta_{j}^{N G}\left(\sum_{n=1}^{N} \mathrm{X}_{j, t+n}\right)^{N G}+\mathrm{e}_{i, t+n^{*}}
\end{gathered}
$$

The variable $\left(\Sigma X_{j, t+n}\right)^{P S}$ takes on the value of $\Sigma X_{j, t+n}$ when $\sum X_{j, t+n}$ is positive and takes on the value " 0 " if $\sum X_{j, t+n}$ is otherwise. Conversely, $\left(\sum X_{j, t+n}\right)^{N G}$ takes on the value of $\sum X_{j, t+n}$ if $\sum X_{j, t+n}$ is negative and takes on the value " 0 " if $\sum X_{j, t+n}$ is otherwise. If the excess return on country funds responds in an asymmetric fashion to innovation in the financial variable $X_{j}$, the coefficients $\beta_{j}{ }^{P S}$ and $\beta_{j}^{N G}$ will differ.

Although we found little evidence of an asymmetric response of the funds' excess returns with regard to the local stock market $(R F S T)$ or exchange rate $(R E X)$ in both univariate and multivariate regressions, we did find evidence of asymmetry in the response to other financial variables. Table $8.8 \mathrm{~B}$ presents the results of one multivariate specification where we allowed for asymmetric effects of $R W R D, R S P$, and $R S M L-R S P$, for return horizons of one, four, and thirteen weeks. Two results stand out. First, at the one-week return horizon, but not at the four- or thirteen-week horizon, we find a significant asymmetric response of country fund excess returns to the excess small firm return $(R S M L-R S P)$. The oversensitivity to $R S M L-R S P$ exists exclusively in a down market. That is, when negative sentiment unrelated to fundamentals affects individual investors, it (negatively) affects their demand for country funds to a larger extent than positive sentiment would. Second, using the four- and thirteen-week holding period returns, we found evidence of a significant asymmetric exposure of fund excess returns to world stock returns $(R W R D)$. Specifically, the excess country fund returns are more greatly exposed to negative world stock returns than they are to positive world stock returns. That the asymmetry is strongest at long horizons suggests that investors overreact much 


\begin{tabular}{|c|c|c|c|c|c|c|c|c|c|c|c|c|}
\hline \multirow{3}{*}{$\begin{array}{l}\text { Return } \\
\text { Horizon }\end{array}$} & \multicolumn{9}{|c|}{ Slope Coefficients and $t$-statistics } & \multirow{3}{*}{\multicolumn{2}{|c|}{$\begin{array}{cc} & \begin{array}{c}\text { Test of No } \\
\text { Asymmetries }\end{array} \\
\text { Adjusted } R^{2} & (p \text {-value })\end{array}$}} & \multirow[b]{3}{*}{ Observations } \\
\hline & \multirow[b]{2}{*}{$D I S C$} & \multirow[b]{2}{*}{$\sum R F S T$} & \multirow[b]{2}{*}{$\sum R E X$} & \multicolumn{2}{|c|}{$\sum R W R D$} & \multicolumn{2}{|c|}{$\sum R S P$} & \multicolumn{2}{|c|}{$\sum R S M L-\Sigma R S P$} & & & \\
\hline & & & & $(+)$ & $(-)$ & $(+)$ & $(-)$ & $(+)$ & $(-)$ & & & \\
\hline $\begin{array}{l}1 \text { week } \\
(N=1)\end{array}$ & $\begin{array}{l}-0.070 \\
(-10.8)\end{array}$ & $\begin{array}{c}-0.184 \\
(-6.58)\end{array}$ & $\begin{array}{c}-0.532 \\
(-8.48)\end{array}$ & $\begin{array}{r}0.279 \\
(3.29)\end{array}$ & $\begin{array}{r}0.372 \\
(4.74)\end{array}$ & $\begin{array}{c}0.472 \\
(4.78)\end{array}$ & $\begin{array}{c}0.350 \\
(3.94)\end{array}$ & $\begin{array}{c}-0.141 \\
(-1.55)\end{array}$ & $\begin{array}{c}0.573 \\
(5.10)\end{array}$ & 0.12 & 0.00 & 6469 \\
\hline $\begin{array}{l}4 \text { weeks } \\
(N=4)\end{array}$ & $\begin{array}{c}-0.183 \\
(-11.8)\end{array}$ & $\begin{array}{r}-0.141 \\
(-5.71)\end{array}$ & $\begin{array}{c}-0.224 \\
(-4.00)\end{array}$ & $\begin{array}{c}0.366 \\
(4.99)\end{array}$ & $\begin{array}{c}0.592 \\
(6.50)\end{array}$ & $\begin{array}{c}0.085 \\
(1.19)\end{array}$ & $\begin{array}{r}0.087 \\
(0.89)\end{array}$ & $\begin{array}{r}0.240 \\
(3.16)\end{array}$ & $\begin{array}{c}0.365 \\
(4.20)\end{array}$ & 0.19 & 0.08 & 6367 \\
\hline $\begin{array}{l}13 \text { weeks } \\
(N=13)\end{array}$ & $\begin{array}{c}-0.442 \\
(-12.1)\end{array}$ & $\begin{array}{c}-0.102 \\
(-1.24)\end{array}$ & $\begin{array}{c}-0.122 \\
(-3.78)\end{array}$ & $\begin{array}{r}0.248 \\
(2.08)\end{array}$ & $\begin{array}{c}0.639 \\
(4.62)\end{array}$ & $\begin{array}{r}-0.023 \\
(-0.19)\end{array}$ & $\begin{array}{c}0.124 \\
(0.99)\end{array}$ & $\begin{array}{r}0.182 \\
(1.73)\end{array}$ & $\begin{array}{c}0.222 \\
(2.18)\end{array}$ & 0.37 & 0.00 & 6061 \\
\hline
\end{tabular}

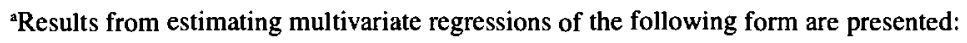

$$
\begin{gathered}
\left(\sum_{n=1}^{N} R F N D_{i, t+n}-\sum_{n=1}^{N} R N A V_{i, t+n}\right)=\beta_{0}+\beta_{1} D I S C_{i, t}+\beta_{2} \sum_{n=1}^{N} R F S T_{t, t+n}+\beta_{3} \sum_{n=1}^{N} \operatorname{REX}_{i, t+n}+\beta_{4}^{P S}\left(\sum_{n=1}^{N} R W R D_{t+n}\right)^{P S} \\
+\beta_{s}{ }^{P S}\left(\sum_{n=1}^{N} R S P_{t+n}\right)^{P S}+\beta_{6}{ }^{P S}\left(\sum_{n=1}^{N}\left(R S M L_{t+n}-R S P_{t+n}\right)\right)^{P S}+\beta_{4}^{N G}\left(\sum_{n=1}^{N} R W R D_{t+n}\right)^{N G}+\beta_{s}^{N G}\left(\sum_{n=1}^{N} R S P_{t+n}\right)^{N G}+\beta_{6}^{N G}\left(\sum_{n=1}^{N^{\prime}}\left(\operatorname{RSML}_{t+n}-R_{t} S P_{t+n}\right)\right)^{N G}+e_{i, t+n^{\prime}}
\end{gathered}
$$

Results for cumulative return horizons of one, four, and thirteen weeks $(N=1,4,13)$ are presented. The equations are estimated by stacking the country funds returns data so as to restrict the slope coefficients on the independent variables to be the same across funds. Numbers in parentheses are $t$ statistics corrected for conditional heteroscedasticity (for $N=1$ ) and autocorrelation of order $N-1$ (for $N=4,13$ ) using the methods in White 1980 and Newey and West 1987, respectively. The second to last column reports the $p$-value associated with the null hypothesis that the excess country fund returns display no asymmetries with respect to the financial variables, $\Sigma R W R D, \Sigma R S P$, and ( $\Sigma R S M L-\Sigma R S M L)$. 
more strongly, over time, to negative news about world fundamentals than they do to positive news about world fundamentals.

\subsubsection{The Time-Varying Risk Hypothesis and Market Segmentation}

It is conceivable that the explanatory variables in the regressions in table 8.8A capture the influence of time-varying risk premia in a model with market segmentation. If markets are segmented, innovations in the ratio of the domestic price of risk to the foreign market price of risk can affect the discounts. Such variation can result from changes in the volatility of domestic relative to foreign stock returns. All else constant, an increase in the domestic price of risk will reduce the price of the fund (and increase the discount), and at the same time reduce the domestic market price index. An increase in the foreign price of risk will reduce the NAV (and lower the discount) while lowering the foreign market price index. Compared to the fund price, the effect of segmentation would be to make the NAV more highly correlated with the local market index $(R F S T)$, and less correlated with the domestic market indices (RSP, $R S M L)$. Moreover, because the discount would reflect the ratio of the domestic price of risk to the foreign market price of risk, the discount would help predict the excess return on a fund.

The hypothesis of time-varying risk (as an explanation of time-varying fund discounts) can be tested without the need to model risk explicitly. To do this, we divided our sample of funds according to whether their host equity markets are restricted or unrestricted. In each group of funds, we regressed the excess fund return ( $R F N D-R N A V)$ on the earlier set of explanatory variables. If market segmentation plays a role in the results in table $8.8 \mathrm{~A}$ then $R F N D-R N A V$ will be more sensitive to foreign stock returns and less sensitive to U.S. (and world) stock returns for funds whose host countries restrict capital movements. Table 8.9 contains the results of these regressions as well as tests of coefficient differences along the two groups of funds. In the oneweek return horizon the differences between the betas on the U.S. market indices $(R S P$ and $R S M L-R S P$ ) are not statistically significant ( $p$-values $=0.99$ and 0.63). Interestingly, the exposure of $R F N D-R N A V$ of the restricted funds to the local market stock index $(R F S T)$ is significantly smaller than the exposure of the unrestricted funds to the same variable ( $p$-value $=0.07$ ). At the four-week return horizon, the differences in domestic market betas remain statistically insignificant, while the foreign market beta of the restricted funds remains significantly lower than that of the unrestricted funds. At the thirteenweek horizon, none of the observed betas differ significantly across the two groups. Thus, the overall results show no strong evidence that market segmentation plays a role in the time-variation in discounts. Consequently, models of time-varying risk premia may have a difficult time explaining the variability of excess fund returns. Explicitly modeling the time-variation in the ratio of the foreign to domestic price of risk is left to future research. 
A. Cumulative Return Horizon Is One Week $(N=1)$

Slope Coefficients and $t$-statistics

\begin{tabular}{|c|c|c|c|c|c|c|c|c|}
\hline $\begin{array}{l}\text { Market Status } \\
\text { (number of funds) }\end{array}$ & DISC & $\sum R F S T$ & $\sum R E X$ & $\sum R W R D$ & $\sum R S P$ & $\Sigma R S M L-\Sigma R S P$ & Adjusted $R^{2}$ & Observations \\
\hline Restricted & 0.069 & -0.113 & 0.188 & 0.482 & 0.395 & 0.345 & 0.12 & 2238 \\
\hline (13) & $(8.38)$ & $(-4.07)$ & (1.13) & $(6.19)$ & $(4.57)$ & $(3.86)$ & & \\
\hline Unrestricted & 0.069 & -0.244 & -0.601 & 0.311 & 0.394 & 0.160 & 0.12 & 4231 \\
\hline$(21)$ & $(7.65)$ & $(-5.03)$ & $(-9.37)$ & $(4.86)$ & $(5.68)$ & $(2.17)$ & & \\
\hline \multirow{2}{*}{\multicolumn{9}{|c|}{$\begin{array}{l}\text { Test of subsample } \\
\text { differences ( } p \text { - }\end{array}$}} \\
\hline & & & & & & & & \\
\hline value) & 0.75 & 0.07 & 0.00 & 0.03 & 0.99 & 0.63 & - & - \\
\hline
\end{tabular}

B. Cumulative Return Horizon Is Four Weeks $(N=4)$

\begin{tabular}{|c|c|c|c|c|c|c|c|c|}
\hline \multirow{2}{*}{$\begin{array}{l}\text { Market Status } \\
\text { (number of funds) }\end{array}$} & \multicolumn{6}{|c|}{ Slope Coefficients and $t$-statistics } & \multirow[b]{2}{*}{ Adjusted $R^{2}$} & \multirow[b]{2}{*}{ Observations } \\
\hline & $D I S C$ & $\sum R F S T$ & $\sum R E X$ & $\sum R W R D$ & $\sum R S P$ & $\Sigma R S M L-\Sigma R S P$ & & \\
\hline $\begin{array}{l}\text { Restricted } \\
\text { (13) }\end{array}$ & $\begin{array}{r}0.182 \\
(9.61)\end{array}$ & $\begin{array}{l}-0.074 \\
(-2.19)\end{array}$ & $\begin{array}{c}0.159 \\
(0.93)\end{array}$ & $\begin{array}{r}0.532 \\
(6.19)\end{array}$ & $\begin{array}{r}0.180 \\
(1.92)\end{array}$ & $\begin{array}{c}0.351 \\
(4.68)\end{array}$ & 0.22 & 2199 \\
\hline $\begin{array}{l}\text { Unrestricted } \\
(21)\end{array}$ & $\begin{array}{r}0.183 \\
(8.48)\end{array}$ & $\begin{array}{l}-0.196 \\
(-5.60)\end{array}$ & $\begin{array}{l}-0.290 \\
(-4.90)\end{array}$ & $\begin{array}{r}0.482 \\
(7.36)\end{array}$ & $\begin{array}{r}0.064 \\
(0.94)\end{array}$ & $\begin{array}{r}0.277 \\
(4.94)\end{array}$ & 0.18 & 4168 \\
\hline $\begin{array}{l}\text { Test of subsample } \\
\text { differences ( } p \text { - } \\
\text { value) } \\
\text { (continued) }\end{array}$ & 0.96 & 0.01 & 0.01 & 0.64 & 0.31 & 0.43 & - & - \\
\hline
\end{tabular}


C. Cumulative Return Horizon Is Thirteen Weeks $(N=13)$

\begin{tabular}{|c|c|c|c|c|c|c|c|c|}
\hline \multirow{2}{*}{$\begin{array}{l}\text { Market Status } \\
\text { (number of funds) }\end{array}$} & \multicolumn{6}{|c|}{ Slope Coefficients and $t$-statistics } & \multirow[b]{2}{*}{ Adjusted $\mathrm{R}^{2}$} & \multirow[b]{2}{*}{ Observations } \\
\hline & DISC & $\sum R F S T$ & $\sum R E X$ & $\sum R W R D$ & $\sum R S P$ & $\sum R S M L-\sum R S P$ & & \\
\hline Restricted & 0.482 & -0.098 & 0.243 & 0.555 & 0.083 & 0.236 & 0.43 & 2082 \\
\hline (13) & $(10.5)$ & $(-2.34)$ & $(1.08)$ & $(3.39)$ & $(0.45)$ & $(2.08)$ & & \\
\hline Unrestricted & 0.409 & -0.151 & -0.157 & 0.414 & 0.127 & 0.138 & 0.33 & 3079 \\
\hline (21) & $(8.13)$ & $(-3.08)$ & $(-1.73)$ & $(3.60)$ & $(1.15)$ & $(1.90)$ & & \\
\hline \multirow{2}{*}{\multicolumn{9}{|c|}{$\begin{array}{c}\text { Test of subsample } \\
\text { differences }(p-\end{array}$}} \\
\hline & & & & & & & & \\
\hline value) & 0.29 & 0.41 & 0.10 & 0.46 & 0.81 & 0.46 & - & - \\
\hline
\end{tabular}

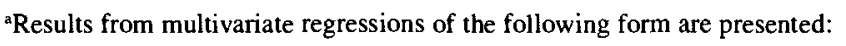

$$
\begin{gathered}
\left(\sum_{n=1}^{N} R F N D_{i, t+n}-\sum_{n=1}^{N} R N A V_{i, t+n}\right)=\beta_{0}+\beta_{1} D I S C_{i, t}+\beta_{2} \sum_{n=1}^{N} R F S T_{i, t+n}+\beta_{3} \sum_{n=1}^{N} R E X_{i, t+n}+\beta_{4} \sum_{n=1}^{N} R W R D_{t+n}+\beta_{5} \sum_{n=1}^{N} R S P_{t+n} \\
+\beta_{6} \sum_{n=1}^{N}\left(R S M L_{t+n}-R S P_{t+n}\right)+e_{i, t+n^{*}}
\end{gathered}
$$

The sample of country funds is divided into two groups, each representing funds investing in restricted and unrestricted equity markets, respectively. The regressions are estimated for cumulative return horizons of one, four, and thirteen weeks $(N=1,4,13)$ and are presented in panels $\mathrm{A}$, B, and $\mathrm{C}$, respectively. The equations are estimated by stacking the country funds returns data so as to restrict the slope coefficients on the independent variables to be the same across country funds within each group. Numbers in parentheses are $t$-statistics corrected for conditional heteroscedasticity (panel A) and autocorrelation of order $N-1$ (panels B and C) using the methods in White (1980) and Newey and West (1987), respectively. The last line in each panel reports the $p$-values associated with the null hypothesis that the coefficients are equal across the two groups of funds. See the text for a description of the classification into restricted and unrestricted funds. 


\subsubsection{Emerging Equity Markets Versus Developed Equity Markets}

In the last few years, a number of foreign stock markets have become increasingly liquid and have emerged as vehicles for international investment. The International Finance Corporation classifies the stock markets of the following countries represented in our sample of country funds as "emerging markets": Portugal, Turkey, Mexico, Brazil, Chile, the Philippines, India, Indonesia, Malaysia, Korea, Thailand, and Taiwan. Because these markets are new to U.S. investors, information about fundamentals affecting asset prices in these countries may be harder (or costlier) to collect and interpret. As a result, the country fund price may be sticky with respect to developments in the emerging markets which affect fundamentals. Conversely, U.S. investors might place undue reliance on information on U.S. fundamentals as a substitute for fundamentals in the foreign market. To test for differences between emerging and developed markets, we divided our sample of funds according to whether the host market is developed or emerging, and for each group regressed the excess fund return $R F N D-R N A V$ on the financial variables in multivariate regressions.

Table 8.10 contains the results of these regressions along with tests of coefficient differences along the emerging and developed funds. The results for return horizons of one, four, and thirteen weeks are presented in panels A, B, and $C$, respectively. In the one-, four-, and thirteen-week horizons, the betas of excess returns $(R F N D-R N A V)$ of the emerging-market funds are generally more highly exposed to U.S. and world risk than are the excess returns of the developed-market funds. However, these differences are far from statistically significant. There is weak evidence, on the other hand, that the excess sensitivity of emerging-market funds to the excess return on small-cap U.S. firms is greater than the corresponding exposure of the developed markets ( $p$-values $=$ 0.1 in panel $\mathrm{A}, 0.05$ in panel B). Speculative bullishness by individuals for small firms may coincide with small investor sentiment for small countries.

\subsubsection{Regional Differences and Trading Hours Mismatch}

As noted in our data section, the period over which the fund return is computed does not exactly overlap with the period over which the NAV return is computed. This mismatch arises because the local currency net asset value of the country funds is computed on the basis of the market prices prevailing at the close of stock trading in the host country. The fund's price in dollars, however, is computed on the basis of the last market transaction closest to the close of trading on the New York or American stock exchanges. Thus, fund prices and NAVs are only approximately synchronous.

Nonsynchronous returns data may introduce biases in the return-generating equations estimated above, especially for the one-week horizon returns. For example, suppose that the U.S. and foreign fundamentals are correlated, and a country fund's price observations are matched with the weekly close of the U.S. market, while its NAV is matched with the weekly close of the local mar- 
A. Cumulative Return Horizon Is One Week $(N=1)$

\begin{tabular}{|c|c|c|c|c|c|c|c|c|}
\hline \multirow{2}{*}{$\begin{array}{l}\text { Market Status } \\
\text { (number of funds) }\end{array}$} & \multicolumn{6}{|c|}{ Slope Coefficients and $t$-statistics } & \multirow[b]{2}{*}{ Adjusted $R^{2}$} & \multirow[b]{2}{*}{ Observations } \\
\hline & $D I S C$ & $\Sigma R F S T$ & $\Sigma R E X$ & $\sum R W R D$ & $\Sigma R S P$ & $\Sigma R S M L-\Sigma R S P$ & & \\
\hline Emerging & 0.064 & -0.167 & -0.337 & 0.415 & 0.393 & 0.310 & 0.10 & 3120 \\
\hline (18) & (7.97) & $(-5.06)$ & $(-2.51)$ & $(5.83)$ & $(4.72)$ & $(3.52)$ & & \\
\hline Developed & 0.079 & -0.222 & -0.661 & 0.343 & 0.372 & 0.141 & 0.14 & 3349 \\
\hline (16) & $(7.17)$ & $(-5.19)$ & $(-10.6)$ & $(4.94)$ & $(5.36)$ & $(2.00)$ & & \\
\hline \multicolumn{9}{|l|}{$\begin{array}{c}\text { Test of subsample } \\
\text { differences ( } p \text { - }\end{array}$} \\
\hline value) & 0.27 & 0.31 & 0.03 & 0.47 & 0.84 & 0.13 & - & - \\
\hline
\end{tabular}

B. Cumulative Retum Horizon Is Four Weeks $(N=4)$

Slope Coefficients and $t$-statistics

\begin{tabular}{|c|c|c|c|c|c|c|c|c|}
\hline $\begin{array}{l}\text { Market Status } \\
\text { (number of funds) }\end{array}$ & $D I S C$ & $\sum R F S T$ & $\sum R E X$ & $\sum R W R D$ & $\sum R S P$ & $\sum R S M L-\Sigma R S P$ & Adjusted $R^{2}$ & Observations \\
\hline Emerging & 0.161 & -0.152 & -0.121 & 0.542 & 0.159 & 0.366 & 0.20 & 3066 \\
\hline (13) & (8.94) & $(-5.82)$ & $(-1.29)$ & $(7.18)$ & (1.86) & $(5.44)$ & & \\
\hline Developed & 0.227 & -0.059 & -0.353 & 0.408 & 0.007 & 0.187 & 0.19 & 3301 \\
\hline (21) & $(7.92)$ & $(-0.90)$ & $(-5.85)$ & (5.34) & $(0.10)$ & $(3.20)$ & & \\
\hline \multirow{2}{*}{$\begin{array}{l}\text { Test of subsample } \\
\text { differences ( } p \text { - } \\
\text { value) }\end{array}$} & & & & & & & & \\
\hline & 0.05 & 0.18 & 0.04 & 0.21 & 0.16 & 0.05 & - & - \\
\hline
\end{tabular}


C. Cumulative Return Horizon Is Thirteen Weeks $(N=13)$

Slope Coefficients and $t$-statistics

\begin{tabular}{|c|c|c|c|c|c|c|c|c|}
\hline $\begin{array}{l}\text { Market Status } \\
\text { (number of funds) }\end{array}$ & $D I S C$ & $\Sigma R F S T$ & $\Sigma R E X$ & $\sum R W R D$ & $\sum R S P$ & $\sum R S M L-\sum R S P$ & Adjusted $R^{2}$ & Observations \\
\hline $\begin{array}{l}\text { Emerging } \\
\text { (18) }\end{array}$ & $\begin{array}{r}0.385 \\
(8.85)\end{array}$ & $\begin{array}{l}-0.159 \\
(-4.58)\end{array}$ & $\begin{array}{r}-0.177 \\
(-1.57)\end{array}$ & $\begin{array}{r}0.473 \\
(3.09)\end{array}$ & $\begin{array}{r}0.184 \\
(1.15)\end{array}$ & $\begin{array}{c}0.274 \\
(2.98)\end{array}$ & 0.37 & 2904 \\
\hline $\begin{array}{l}\text { Developed } \\
\text { (16) }\end{array}$ & $\begin{array}{r}0.538 \\
(8.30)\end{array}$ & $\begin{array}{l}-0.038 \\
(-0.51)\end{array}$ & $\begin{array}{c}-0.004 \\
(-0.06)\end{array}$ & $\begin{array}{r}0.292 \\
(2.60)\end{array}$ & $\begin{array}{r}0.026 \\
(0.23)\end{array}$ & $\begin{array}{r}0.127 \\
(1.87)\end{array}$ & 0.37 & 3157 \\
\hline $\begin{array}{l}\text { Test of subsample } \\
\text { differences ( } p \text { - } \\
\text { value) }\end{array}$ & 0.05 & 0.02 & 0.19 & 0.33 & 0.42 & 0.20 & - & - \\
\hline
\end{tabular}

${ }^{2}$ Results from estimating multivariate regressions of the following form are presented:

$$
\begin{gathered}
\left(\sum_{n=1}^{N} R F N D_{i, t+n}-\sum_{n=1}^{N} R N A V_{i, t+n}\right)=\beta_{0}+\beta_{1} D I S C_{i, t}+\beta_{2} \sum_{n=1}^{N} R F S T_{t, t+n}+\beta_{3} \sum_{n=1}^{N} R E X_{i, t+n}+\beta_{4} \sum_{n=1}^{N} R W R D_{t+n}+\beta_{5} \sum_{n=1}^{N} R S P_{t+n} \\
+\beta_{6} \sum_{n=1}^{N}\left(R S M L_{t+n}-R S P_{t+n}\right)+e_{i, t+n}
\end{gathered}
$$

The sample of country funds is divided into two groups, each representing either funds investing in emerging markets or funds investing in developed markets. The regressions are estimated for cumulative return horizons of one, four, and thirteen weeks $(N=1,4,13)$ and are presented in panels $\mathrm{A}$, B, and $\mathrm{C}$, respectively. The equations are estimated by stacking the country funds returns data so as to restrict the slope coefficients on the independent variables to be the same across country funds within each group. Numbers in parentheses are $t$-statistics corrected for conditional heteroscedasticity (panel A) and autocorrelation of order N-1 (panels B and C) using the methods in White (1980) and Newey and West (1987), respectively. The last line in each panel reports the $p$-values associated with the null hypothesis that the coefficients are equal across the two groups of funds. See the text for a description of the classification of funds into the emerging and developed samples. 
ket. Then both the correlation of the fund's return with the foreign market and the correlation of the NAV return with the U.S. market will be biased downward. As a result, the excess return on the fund may display an excess negative correlation with the foreign market and an excess positive correlation with the U.S. market, even if both fund and NAV reflect fundamental information. These biases will be least severe for funds whose host countries have trading hours most synchronous with the U.S. markets, and most severe for funds investing in countries whose trading hours are least synchronous.

To examine whether nonsynchronous data can explain part of the correlations observed in table $8.8 \mathrm{~A}$, we partitioned our sample into three groups based on the geographical region: East Asian (including Australia) funds, European (including Turkey) funds, and Latin American funds. The Latin American funds' NAV data are the most synchronous with the actual price data from New York trading. The East Asian funds are the least synchronous. For each geographic group, we regressed the one-week excess fund return, $R F N D-R N A V$, on the explanatory variables. If nonsynchronous trading accounts for part of the results in table 8.8A, then the RFND - RNAV of the East Asian funds will have the greatest (positive) exposure to U.S. stock returns, and the greatest (negative) exposure to local stock returns. Excess returns on Latin American would have the least exposure to both U.S. and local stock returns.

Table 8.11 contains the results of the regressions for the one-week holdingperiod horizon (where biases would be most important). The European funds have greater exposure to the local market stock returns (RFST) than either the Asian or Latin American funds. These differences are statistically significant in each case. Meanwhile, there is no significant difference between the betas of the Asian and Latin American funds with respect to the foreign stock returns. The excess returns of the Latin American funds have more exposure to the U.S. return indices ( $R S P$ and $R S M L-R S P$ ) than do the Asian or European funds, even though the Latin funds suffer less from nonsynchronous price/ NAV observations. This difference is statistically significant for the beta with the large U.S. firm index, $R S P$, although insignificant for $R S P-R S M L$. Thus, the findings in table 8.11 do not support the hypothesis that nonsynchronous data play a role in the findings of table $8.8 \mathrm{~A}$.

\subsection{Conclusion}

This paper examined the weekly price behavior of thirty-five country funds that traded on the New York and American stock exchanges between 1985 and 1993. The aim was to characterize some basic empirical regularities of country fund prices and to examine the extent to which the noise-trader model of asset prices is consistent with the regularities.

Unlike domestic-equity funds, not all country funds trade at an average discount. However, controlling for the effect of cross-border restrictions, we find 


\begin{tabular}{|c|c|c|c|c|c|c|c|c|}
\hline \multirow{2}{*}{$\begin{array}{l}\text { Region } \\
\text { (number of funds) }\end{array}$} & \multicolumn{6}{|c|}{ Slope Coefficients and $t$-statistics } & \multirow[b]{2}{*}{ Adjusted $R^{2}$} & \multirow[b]{2}{*}{ Observations } \\
\hline & DISC & $\sum R F S T$ & $\sum R E X$ & $\sum R W R D$ & $\Sigma R S P$ & $\Sigma R S M L-\Sigma R S P$ & & \\
\hline East Asian Funds & 0.068 & -0.157 & -0.438 & 0.460 & 0.358 & 0.238 & 0.11 & 2406 \\
\hline (13) & $(8.08)$ & $(-5.25)$ & $(-5.77)$ & $(5.77)$ & $(4.34)$ & $(2.54)$ & & \\
\hline European & 0.073 & -0.278 & -0.670 & 0.425 & 0.317 & 0.176 & 0.14 & 3097 \\
\hline$(15)$ & $(6.94)$ & $(-7.23)$ & $(-11.0)$ & $(5.88)$ & $(4.29)$ & $(2.39)$ & & \\
\hline Latin American & 0.064 & -0.139 & -0.327 & 0.139 & 0.648 & 0.301 & 0.08 & 966 \\
\hline (6) & $(3.62)$ & $(-2.00)$ & $(-1.97)$ & $(1.07)$ & $(3.49)$ & $(1.75)$ & & \\
\hline
\end{tabular}

${ }^{2}$ Results from estimating multivariate regressions of the following form are presented:

$$
\begin{gathered}
\left(\sum_{n=1}^{N} R F N D_{i, t+n}-\sum_{n=1}^{N} R N A V_{i, t+n}\right)=\beta_{0}+\beta_{1} D I S C_{i, t}+\beta_{2} \sum_{n=1}^{N} R F S T_{i, t+n}+\beta_{3} \sum_{n=1}^{N} R E X_{i, t+n}+\beta_{4} \sum_{n=1}^{N} R W R D_{i, t+n}+\beta_{5} \sum_{n=1}^{N} R S P_{t+n} \\
+\beta_{6} \sum_{n=1}^{N^{\prime}}\left(R S M L_{t+n}-R S P_{t+n}\right)+e_{i, t+n^{*}}
\end{gathered}
$$

The sample of country funds is divided into three groups representing funds investing in the Far East, Europe, and Latin America, respectively. Regressions are estimated for cumulative return horizons of one week $(N=1)$. The equations are estimated by stacking the country funds returns data so as to restrict the slope coefficients on the independent variables to be the same across country funds within each group. Numbers in parentheses are $t$-statistics corrected for conditional heteroscedasticity using the method in White (1980). 
that country funds adhere to the stylized facts established for domestic-equity funds: in the long run, discounts prevail for funds whose host countries allow free cross-border capital movements. Like their domestic-equity counterparts, country funds are typically issued at a premium, and this premium erodes by about 20 percent over the twenty-four weeks that follow the IPO. The deterioration in the premium is the same for funds invested in restricted markets and those invested in unrestricted markets.

The noise-trading model of DeLong et al. (1990) can easily explain the previous evidence. The average discount for funds invested in countries with no restrictions on capital movements is attributable to noise-trader risk, which depresses fund prices relative to the NAVs. The premium at the initiation of a country fund is explained by the ability of fund organizers to time the issuance of country funds to coincide with positive investor sentiment. The subsequent decline in the premium is explained by mean-reversion in investor sentiment.

Discounts vary substantially over time and contribute to a variance in country fund returns which is generally three times greater than the variance of the return on the underlying assets. However, discounts are largely stationary, implying either that the NAV captures information about fundamental value not captured in the fund price (that is, the fund is mispriced); the fund price contains information about the fundamental value not captured in the market value of the underlying assets; or both the fund price and the NAV carry fundamental information not captured by the other. Regressions of fund returns and NAV returns on discounts suggest that the discount has significant predictive power for the fund return, but little predictive power for the NAV return. This asymmetry suggests that mean-reverting sentiment is an important component of the price of the country funds but not in the market value of the underlying assets, so that it is the fund which is primarily mispriced. This is consistent with the idea that compared to the investor clienteles of country funds' underlying assets (presumably foreign institutions and individuals), U.S. individuals, the investor clientele of country funds, are prone to trade on sentiment and to misperceive fundamental value.

Estimation of an unobserved components model on the discounts of the nine oldest funds reveals a common component which is strongly persistent. This common and persistent behavior is consistent with the structure imposed on the noise-trader model by DeLong et al. (1990), which requires that variation in sentiment be systematic if it is to be priced in equilibrium. The common component we estimate accounts for roughly 20 percent of the variance of weekly country fund discounts. Examination of the estimated common component reveals that systematic variation in sentiment may be driven in part by widely noted world events such as the fall of the Berlin Wall in 1990. In the aftermath of this event, country fund IPOs peaked.

To capture the source of part of the variation in discounts over time, we ran regressions of the fund return, the NAV return, and their difference-the excess fund return-on returns of a number of aggregate financial variables. We 
find that fund prices are "sticky," that is, they do not move as much as their respective NAVs with respect to movements in the host country's aggregate stock market. Similarly, fund prices, which are quoted in dollars, are sticky with respect to exchange-rate revaluations, although this is largely a shorthorizon phenomenon. On the other hand, fund prices are overly sensitive to movements in world stock returns and to U.S. stock returns as captured by the Standard and Poor's 500. The oversensitivity to the world stock market index is present for all holding-period horizons that we examine. Hence, if discounts reflect the sentiment and misperceptions of the country funds' investor clientele, then this sentiment is partly driven by "world" fundamentals.

The excess return on U.S. small firms, which are predominantly traded by individual investors, is also a significant factor in explaining contemporaneous country fund excess returns. Country fund prices are overly sensitive to the small-firm/large-firm return differential. This result is robust to the inclusion of other financial variables correlated with fund discounts, and is also robust to the return horizon. The finding upholds Lee, Shleifer, and Thaler's (1991) idea that sentiment, if it is systematic, will affect assets with little fundamental similarity to country funds except that they share the same investor clientele, namely individual U.S. investors.

A model of rational traders could potentially explain the above correlations if the model were enriched by introducing sufficient frictions. However, we provide evidence which casts doubt on the ability of rational models in the context of market imperfections to explain variation in country fund discounts. First, apart from the evidence on the average discounts, we find no evidence that the discounts of funds whose host countries restrict cross-border equity investments behave differently from the discounts of funds that invest in unrestricted markets. Moreover, we also find little evidence in favor of market frictions caused by informational factors, or by nonsynchronous data. For example, the excess returns of funds invested in emerging markets, where information about fundamentals may be harder or costlier to obtain, do not exhibit a higher correlation with the U.S. market than the excess returns of country funds in developed markets. Similarly, the excess returns of funds whose price and NAV data suffer from the most time-mismatch do not generally exhibit higher correlations with the U.S. market. Overall, the facts we uncover present a challenge to asset-pricing models based on fully rational international investors.

\section{References}

Ammer, John M. 1990. Expenses, yields, and excess returns: New evidence on closedend fund discounts from the UK. Financial Markets Group Discussion Paper no. 108. London School of Economics. 
Anderson, Seth Copeland. 1986. Closed-end funds versus market efficiency. Journal of Portfolio Management, fall, 63-65.

Bailey, Warren, and Joseph Lim. 1992. Evaluating the diversification benefits of the new country funds. Journal of Portfolio Management, spring, 74-80.

Barker, David. 1991. Cross-sectional variation in closed-end fund discounts. University of Chicago. Manuscript.

Bodurtha, James N., Dong-Soo Kim, and Charles M. C. Lee. 1993. Closed-end country funds and U.S. market sentiment. Working paper, University of Michigan.

Bonser-Neal, Catherine, Greggory Brauer, Robert Neal, and Simon Wheatley. 1990. International investment restrictions and closed-end country fund prices. Journal of Finance 45:523-47.

Boudreaux, Kenneth. 1973. Discounts and premiums on closed-end mutual funds: A study in valuation. Journal of Finance, May, 515-22.

Brauer, Greggory A. 1984. "Open-ending" closed-end funds. Journal of Financial Economics 13 (December): 491-508.

- 1988. Closed-end fund shares' abnormal returns and the information contents of discounts and premiums. Journal of Finance 43 (1): 113-27.

1992. Closed-end mutual funds. In The new Palgrave dictionary of money and finance, eds. Peter Newman, Murray Milgate, and John Eatwell. London: Macmillan.

Brickley, J. A., and J. S. Schallheim. 1985. Lifting the lid on closed-end investment companies: A case of abnormal returns. Journal of Quantitative and Financial Analysis 20:107-18.

Chopra, Navin, Charles M. C. Lee, Andrei Shleifer, and Richard Thaler. 1993. Yes, discounts on closed-end funds are a sentiment index. Journal of Finance 48 (June): $801-8$

DeLong, J. Bradford, Andrei Shleifer, Lawrence H. Summers, and Robert Waldmann. 1990. Noise trader risk in financial markets. Journal of Political Economy 98(4): 703-38.

Divecha, Arjun B., Jaime Drach, and Dan Stefek. 1992. Emerging markets: A quantitative perspective. Journal of Portfolio Management, fall, 41-51.

Diwan, Ishac, and Santiago Galindez. 1991. Country funds. Debt and International Finance Division of the World Bank, Washington, D.C. Manuscript.

Diwan, Ishac, Vihang Errunza, and Lemma Senbet. 1992. The pricing of country funds and their role in capital mobilization for emerging economies. Working Paper no. 1058. Debt and International Finance Division of the World Bank, December.

Errunza, Vihang, and Etienne Losq. 1985. International asset pricing under mild segmentation: Theory and tests. Journal of Finance 40 (March): 105-24.

Eun, Cheol, and S. Janakiramanan. 1986. A model of international asset pricing under mild segmentation: Theory and tests. Journal of Finance 41:897-914.

Fredman, Albert J., and George C. Scott. 1991. Investing in closed-end funds: Finding value and building wealth. New York: New York Institute of Finance, Simon and Schuster.

Harvey A. C. 1981. Time series models. Oxford: Phillip Allan.

Jorion, Philippe, and Eduardo Schwartz. 1986. Integration vs. segmentation in the Canadian stock market. Journal of Finance 41(3): 603-15.

Lee, Charles M. C., Andrei Shleifer, and Richard Thaler. 1991. Investor sentiment and the closed-end fund puzzle. Journal of Finance 46(1): 75-109.

Malkiel, Burton G. 1977. The valuation of closed-end investment company shares. Journal of Finance 32(3): 847-60.

1990. A random walk down Wall Street. New York: Norton.

Newey, W., and K. West. 1987. A simple positive-definite heteroskedasticity and autocorrelation consistent covariance matrix. Econometrica 55:703-8. 
Peavey, J. W. 1990. Returns on initial offerings of closed-end funds. Review of Financial Studies 3:695-708.

Pontiff, Jeffrey. 1991. Closed-end fund premia and returns: Implications for financial market equilibrium. William E. Simon Graduate School of Business Administration, University of Rochester. Manuscript.

Richards, R. Malcolm, Don R. Fraser, and John C. Groth. 1980. Winning strategies for closed-end funds. Journal of Portfolio Management, fall, 50-55.

Roenfelt, Rodney L., and Donald Tuttle. 1973. An examination of the discounts and premiums of closed-end investment companies. Journal of Business Research $1: 129-40$.

Roll, Richard. 1992. Industrial structure and the competitive behavior of international stock market indexes. Journal of Finance 47 (March): 3-41.

Rozeff, M. S. 1991. Closed-end fund discounts and premiums. In Pacific Basin Capital Markets Research. Vol. 2:503-22.

Sargent, Thomas J., and Christopher A. Sims. 1977. Business cycle modelling without pretending to have too much a-priori economic theory. In New methods in business cycle research, eds. C. Sims et al. Minneapolis: Federal Reserve Bank of Minneapolis.

Sharpe, William F., and Howard B. Sosin. 1975. Closed-end investment companies in the United States: Risk and return. In European finance association 1974 proceedings, ed. B. Jacquilat. Amsterdam: North Holland.

Shiller, Robert. 1984. Stock prices and social dynamics. Brookings Papers on Economic Activity 2:457-98.

Stock, James, and Mark Watson. 1988. Testing for common trends. Journal of the American Statistical Association 83 (404): 1097-1107.

Thompson, Rex. 1978. The information content of discounts and premiums on closedend fund shares. Journal of Financial Economics 6:151-86.

Weiss, Kathleen. 1989. The post-offering price performance of closed-end funds. $\mathrm{Fi}$ nancial Management, autumn, 57-67.

White, Halbert. 1980. A heteroskedasticity-consistent covariance matrix estimator and direct test for heteroskedasticity. Econometrica 48:817-38.

Zweig, Martin E. 1973. An investor expectations stock price predictive model using closed-end fund premiums. Journal of Finance 28:67-87.

\section{Comment Vihang Errunza}

The paper investigates the behavior of country fund (CF) premium/discounts. After analyzing some basic empirical regularities, the authors test various hypotheses based on noise-trading literature. (See, for example, DeLong et al. 1990 and Lee, Shleifer, and Thaler 1991.) They conclude that the data are consistent with the models of investor sentiment.

In general, the topic is interesting and timely. On balance the empirical tests are conducted with care. To avoid duplication, I do not discuss the issues related to data (e.g., dividend/capital gains distributions), and insights regarding

Vihang Emunza is professor of finance and international business at McGill University. 
discounts on closed-end funds covered by my codiscussant Rob Neal. I focus on the equilibrium determinants of country fund premium/discounts.

The authors seem to suggest that stationary discounts imply noise trading whereas nonstationarity implies market segmentation (section 8.4.4). I do not understand this line of reasoning since market segmentation is consistent with stationarity. Further, 40 to 60 percent of discounts (table 8.5) are nonstationary. Thus, one cannot dismiss the importance of market segmentation. In essence, given the results, a more complete understanding of premium/discounts should include explanations other than noise trading.

There are three approaches that provide insights regarding country fund premia. The traditional literature (e.g., Malkiel 1977 and Brauer 1984) suggests fees, illiquid stocks, and taxes as explanations of the discounts on U.S. closedend funds. Similarly, as argued by the authors, noise-trading models suggest that systematic variations in (individual) investor sentiment would render CFs riskier and underpriced relative to fundamentals, thus leading to discounts on CFs. Of course, this requires that funds and underlying assets are not equally subject to the same variation in noise trader sentiment. Finally, equilibrium models of international asset pricing under barriers to capital flows (e.g., Stulz 1981 and Errunza and Losq 1989) suggest that unrestricted domestic securities will be priced by global risk, and that restricted foreign securities will be priced by global and national risks. Further, if foreign assets can be fully spanned by domestic assets, the national risk premium will disappear. The integrating impact of CFs leads to the conclusion that there will be no premium/discount on CFs. The models implicitly assume perfect cross-border arbitrage.

Thus, the available models deliver discounts or zero premium/discounts on $\mathrm{CFs}$. The reality is, however, quite different. For example, some CFs have fluctuated between substantial premiums and discounts over time (e.g., Malaysia Fund), whereas others have traded consistently at high premiums (e.g., Korea Fund). Moreover, the authors report consistent premiums for the restricted sample (table 8.4). Thus an appropriate model must explain average premiums or discounts for a fund, it must explain the average premium/discount across funds at a given time, and it must explain time-series behavior of premium/discounts.

Diwan, Errunza, and Senbet (1993) develop a new equilibrium international asset pricing model (IAPM) that incorporates barriers to capital flows, imperfect substitution between the $\mathrm{CF}$ and its underlying assets, imperfect arbitrage, and investor sentiment. The model suggests that in equilibrium, the premium/ discount will depend on the degree of access to the originating market, the degree of spanning of foreign assets within the host (U.S.) market, the degree of substitution between the fund and its underlying assets, and the common global country fund premia.' In empirical tests, the authors use the return on

1. The Errunza (1991) model, although it does not explicitly consider investor sentiment, delivers similar results. 
the world market portfolio $\left(R_{w}\right)$, Standard and Poor's 500, and Russell 2000 to capture commonality among funds, whereas Diwan, Errunza, and Senbet [1993] use the value-weighted average premium/discount on U.S.-traded country funds to proxy the common factor. The similarity between the authors' common factor (figure 8.3) and the value-weighted average premium/discounts on U.S.-traded country funds (reported as figure 3 in part I of Diwan, Errunza, and Senbet [1993]) is striking. Further, the time-series and cross-sectional test results of Diwan, Errunza, and Senbet (1993) are consistent with the predictions of the IAPM.

Finally, CFs from perfectly integrated markets (e.g., United Kingdom) should be priced similarly to U.S. closed-end funds. In other words, traditional factors and noise trading should explain their discount behavior. However, the available evidence suggests that most markets are not fully integrated. In a mildly segmented world market structure, the CF premiums/discounts will be determined by the factors suggested by IAPMs, traditional literature, and investor sentiment. In summary, the paper is very interesting but it could benefit from the theoretical insights of IAPMs.

\section{References}

Brauer, G. 1984. Open-ending closed-end funds. Journal of Financial Economics 13:491-508.

DeLong, J., A. Shleifer, L. Summers, and R. Waldmann. 1990. Noise trader risk in financial markets. Journal of Political Economy 98(4): 703-38.

Diwan, I., V. Errunza, and L. Senbet. 1993 Country funds: Theory and evidence. World Bank. Mimeo.

Errunza, V. 1991. Pricing of national index funds. Review of Quantitative Finance and Accounting 1(1): 91-100.

Errunza, V., and E. Losq. 1989. Capital flow controls, international asset pricing and investor's welfare: A multi-country framework. Journal of Finance 44:1025-37.

Lee, C., A. Shleifer, and R. Thaler. 1991. Investor sentiment and the closed-end fund puzzle. Journal of Finance 46(1): 75-109.

Malkiel, B. 1977. The valuation of closed-end investment company shares. Journal of Finance 32:847-59.

Stulz, R. 1981. On the effects of barriers to international investment. Journal of Finance 36:923-34.

\section{Comment Robert Neal}

Closed-end country funds are interesting for two reasons. First, they provide a convenient channel for international funds to be invested in a specific country. This channel can be valuable to countries attempting to attract capital and to 
investors attempting to reduce risk (Diwan, Errunza, and Senbet 1993). Second, closed-end funds are now the subject of spirited debate. A recent paper by Lee, Shleifer, and Thaler (1991) has prompted researchers to look outside the conventional model of investor behavior and consider whether investor sentiment can influence returns. Regardless of one's prior beliefs regarding the role of investor sentiment, we can all agree that careful analysis of new data helps our understanding of these issues. Herein lies the key contribution of the paper by Hardouvelis, La Porta, and Wizman. The paper seeks to explain the time-series behavior of country fund returns by using economic factors, as well as proxies for market sentiment. Their approach focuses on the forecast power of discounts and thus should be more convincing to a skeptical reader.

Overall, the paper makes a solid contribution to our understanding of country fund returns. Where the paper falls short, it is due to the large scope of the analysis. The paper provides a model of fund discounts, discusses the stylized facts of country funds, and seeks to resolve the country fund discount puzzle. Given this range of issues, the paper is remarkably thorough. My comments fall into four areas: the noise-trader model, the dividend adjustment process, the cross-correlations between price changes and net asset value changes, and the interpretation of the regression results. Most of my criticisms are already addressed in the paper but I still feel there is room for improvement.

Let me first focus on their model. The paper presents a model of noisetrader risk and country fund discounts. The model can be summarized in the following two relations:

1. $E($ Fund Return $)=a_{i}+b_{i} \operatorname{Cov}($ sentiment innovations, wealth $)+c_{i}$ sentiment, and

2. Discount $t_{i}=b_{i} \operatorname{Cov}$ (sentiment innovations, wealth) $+c_{i}$ sentiment.

In this notation, $a_{i}$ is determined by the fundamentals of the fund. Since the fundamental return can be represented by the NAV return, subtracting the $a_{i}$ from both sides of (1) will yield (2).

In this model, it is necessary to assume that investor sentiment is not perfectly forecastable, cannot be diversified away, and has a stronger effect on fund returns than the average stock. Given these assumptions, investor sentiment can affect fund returns. This holds even if the expected value of the sentiment is zero, as long as the covariance between sentiment innovations and wealth is nonzero. While this framework has an intuitive appeal, it is subject to several criticisms. First, it associates the entire discount movement to investor sentiment innovations. There is no role for nonsentiment factors such as those considered by Malkiel (1977), Brauer (1984), or by Bonser-Neal, Brauer, Neal, and Wheatley (1990). Second, it is possible that country fund sentiment is a proxy for some unspecified time varying risk premium. Neal and Wheatley (1993) show that this is unlikely for domestic funds, but do not extend the analysis to country funds. Third, if markets are segmented to some degree, it is not obvious that the $a_{i}$ will drop out for country funds. Under segmentation, 
the valuation based on the fundamentals may differ for domestic and foreign investors.

A second issue is that the adjustment for dividends can be improved. The paper provides two ways to calculate the change in the premium.

$$
\begin{aligned}
& \left(R_{\text {fund }}-R_{\text {nav }}\right)=\ln \left[\left(\text { Fund Price }_{t}+\text { Dividend }_{t}\right) / \text { Fund Price }_{t-1}\right]-\ln \left[\left(N A V_{t}\right.\right. \\
& \left.\left.+ \text { Dividend }_{t}\right) / N A V_{t-1}\right] \text { and } \\
& \text { DISC } \left.C_{t}=\ln \text { (Fund Price }\right)_{t} / N A V_{r} .
\end{aligned}
$$

These two approaches will produce different values for the changes when precounts (or premiums) are large and the dividend payout is large. For example, suppose the price of a fund is $\$ 30$, the NAV is $\$ 20$, and the dividend is $\$ 5$. Before the dividend, the fund has a 50 percent premium. Suppose that the premium is unaffected by the dividend, so the ex-dividend price is $\$ 22.50$. This implies that the fund return will be negative while the NAV return is zero. Moreover, the adjustment process for large discount or premium funds should probably focus on the announcement date, and not the ex-date. As a practical matter, I doubt that these adjustments would have a large effect on their findings except, perhaps, for the Taiwan Fund, which traded at large premiums and paid large dividends.

A third issue is that some of their results may be influenced by the relatively large cross-correlations between a fund's price and the NAV. For example, in Bonser-Neal, Brauer, Neal, and Wheatley (1990), the average cross-correlation for country funds between the change in price at time $t$ and the change in NAV at time $t-1$ is .24 . Similarly, the average between the change in price, and the change in $\mathrm{NAV}_{t+1}$ is 29 . If these cross-correlations result from nonsynchronous trading or delayed reporting, then the predictive power of discounts to explain subsequent fund returns may be overstated. I doubt that this would have much effect on the regressions in table 8.6 and tables 8.7 through 8.11 , which are based on thirteen-week intervals. However, the cross-correlations certainly have the potential to influence the regressions based on one- and four-week intervals. A related point is that the regressions that are based on the four- and thirteen-week intervals use overlapping data. As Kim and Nelson (1990) have shown, the use of overlapping data can make the regression $R^{2}$ an unreliable measure.

The fourth issue is the author's interpretation of table 8.8A. This table contains the main regression result in the paper: fund returns are regressed against home country returns, the change in exchange rates, the Standard and Poor's 500 return, the world return, U.S. small firm returns, and the lagged discount. Similar regressions are presented using the NAV returns and the difference between fund returns and NAV returns. My interpretation of these regressions is that after controlling for fundamentals, there is evidence that discounts have forecast power, and this is consistent with the noise-trader model. Their interpretation is much stronger. In their view, each of these "fundamental" factors 
reflect innovations in investor sentiment, and significant $t$-statistics for these factors therefore provide additional support for their noise-trader model. As indicated above, however, if markets are segmented, then their conclusion may be unwarranted.

A related issue is that $\mathrm{I}$ found the regression in table $8.8 \mathrm{~B}$ to be unconvincing. This regression is similar to that in table $8.8 \mathrm{~A}$, except that it allows for an asymmetric response to the independent variables. The motivation for this section is that Japanese investors, who supposedly drove up the price of country funds in 1989-90, faced a liquidity constraint when the Japanese market fell in 1990. Hence the performance of funds may differ between up and down markets. They find little evidence of a Japanese effect, but do report an asymmetric effect from the return to the world portfolio. They conclude that small investors overreact more strongly to negative news than to positive news. While this is an interesting result, the link to the existing theory is not obvious, and there is also the possibility that fund managers changed their portfolios in response to anticipated changes in the market.

Finally, it is possible that the forecast power of discounts may reflect common changes in the relative price of risk. If markets are segmented then discounts should be proportional to the ratio of the domestic price of risk to the foreign price of risk. Changes in the domestic price of risk will therefore affect all country fund discounts and could induce a common time-series variation in discounts. It would be interesting to include proxies for the domestic price of risk as another variable in table $8.8 \mathrm{~A}$ regressions. Alternatively, for countries with multiple country funds (Germany, Taiwan, etc.), it would be interesting to see whether funds from the same country behave similarly.

In summary, this paper provides a comprehensive analysis of closed-end country funds. The paper provides many interesting results, including evidence that lagged discounts have predictive power for future fund returns. While the authors' interpret their results as offering strong support for the investor sentiment story, I suggest a more cautious interpretation. I am also concerned that noise-trader models can rationalize almost any behavior. However, I have yet to see a convincing model of discounts that is based on rationality. The least implausible model I have seen is the costly arbitrage model by Pontiff (1993).

\section{References}

Bonser-Neal, C., G. Brauer, R. Neal, and S. Wheatley. 1990. International investment restrictions and closed-end country fund prices. Journal of Finance 45:523-47.

Brauer, G. 1984. Open-ending closed-end funds. Journal of Financial Economics 13:491-507.

Diwan, I., V. Errunza, and L. Senbet. 1993. The pricing of country funds and their role in capital mobilization for emerging economies. Working paper, McGill University.

Lee, C., A. Shleifer, and R. Thaler. 1991. Investor sentiment and the closed-end fund puzzle. Journal of Finance 46:75-109. 
Kim, M., and C. Nelson. 1990. Predictable stock returns: Reality or statistical illusion? Working paper, University of Washington.

Malkiel, B. 1977. The valuation of closed-end investment company shares. Journal of Finance 32:847-60.

Neal, R., and S. Wheatley. 1993. Closed-end fund discounts and the predictability of small firm returns. Working paper, University of Chicago.

Pontiff, J. 1993. Costly arbitage and closed-end fund discounts. Working paper, University of Washington. 